\title{
BKK the EZ Way An International Production Economy with Recursive Preferences
}

\author{
Ric Colacito Max Croce Steven Ho Philip Howard*
}

\begin{abstract}
We characterize an international production economy in which: (1) agents have Epstein and Zin (1989) preferences, (2) international productivity frontiers are exposed to both short- and long-run shocks, and (3) consumption features a larger degree of home bias relative to investment. Under our recursive risk-sharing scheme, relative good long-run news to domestic productivity create a net outflow of domestic investments. This response accounts for the Backus, Kehoe and Kydland (1994) anomaly, concerning the lower degree of correlation of international consumption relative to output. We document that our model is strongly consistent with novel empirical evidence on both international quantities and prices.
\end{abstract}

JEL classification: C62; F31; G12.

First draft: March 31, 2012. This draft: November 16, 2012.

\footnotetext{
${ }^{*}$ All authors are affiliated with the University of North Carolina at Chapel Hill, Kenan-Flagler Business School. We thank Ravi Bansal, David Backus, Karen Lewis, Chris Lundblad, Nick Roussanov, Tom Sargent, Adrien Verdelhan, Stan Zin. We also thank the seminar participants at KenanFlagler Business School (UNC), Fuqua School of Business (Duke University), North Carolina State University, AEA Meetings.
} 


\section{Introduction}

Does capital always flow to the most productive countries? Does it matter whether productivity improvements are deemed to be shortly-lived or long lasting? In this paper we answer these questions by investigating the role of short- and long-term productivity risk on international risk-sharing and capital flows in the context of a general equilibrium model in which agents have recursive preferences.

To assess the relevance of international long-run productivity, we study different risk and production structures and show that introducing asset pricing considerations in the design of the production activity delivers a rich set of novel and testable implications. One of the most important theoretical and empirical findings of our analysis is that countries receiving good long-run productivity news experience capital outflows in the short-run. We obtain this result starting from a frictionless Backus, Kehoe, and Kydland (1994) (henceforth BKK) two-good and two-country production economy modified along three key dimensions.

First, we add Epstein and Zin (1989) (henceforth EZ) recursive preferences and longrun growth shocks in the spirit of the recent long-run risk literature on exchange

rates. As long as the intertemporal elasticity of substitution is larger than the reciprocal of their relative risk aversion, investors dislike both low expected levels of their wealth and increasing uncertainty about their future utility profiles. As shown by Colacito and Croce (2012), in this setting agents look for a risk-sharing arrangement that allows them to smooth future utility, equivalently wealth, in addition to short-term consumption.

Second, we follow Erceg, Guerrieri, and Gust (2008) (henceforth EGG) and assume a larger degree of home bias in consumption than in investment. This is a key difference relative to BKK that assume $88 \%$ of both the consumption and the investment bundles consist of domestic goods, following the empirical observation that total U.S. imports represent about $12 \%$ of total output. Instead Erceg, Guerrieri, and Gust (2008) show that this approach is inconsistent with U.S. data, as foreign consumption goods represent only $3 \%-5 \%$ of the U.S. consumption bundle, whereas foreign investment goods represent about $40 \%$ of U.S. aggregate investment.

Third, we modify the basic BKK model by adding heterogenous exposure of capital 
vintages to aggregate productivity as in $\mathrm{Ai}$, Croce, and Li (2012). Using U.S. firm data, Ai et al. (2012) document that young capital vintages have lower exposure to aggregate productivity risk than older capital vintages. We show that the introduction of this feature enhances all our results and allows us to produce an average annual equity premium of about $3.6 \%$, a number three hundred times bigger than that obtained by BKK.

As shown in prior work (Colacito and Croce 2012), in a frictionless two-good endowment economy featuring complete markets, the optimal recursive risk-sharing scheme produces endogenous time-variation in the distribution of wealth, consumption and currency risk. This result is relevant because it shows that recursive preferences and long-run risk can simultaneously resolve several exchange rate anomalies (Brandt et al. (2006), Backus and Smith (1993), Backus et al. (2001)). When we use a higher home-bias in consumption than in investment as in EGG in the context of a fully fledged production economy, the model produces the right amount of exchange rate volatility and it resolves the Backus et al. (1992) quantity anomaly. This means that our model is able to reproduce the lower degree of correlation of consumption relative to output across countries, which is typically found in the data.

Our resolution of the quantity anomaly relies our most important prediction on international capital flows: good long-run productivity news produce an immediate outflow of investment. The key economic insight behind this result is that our model features a tension between two channels. On the one hand, the productivity channel suggests that resources should move from the least productive to the most productive country; on the other hand, the risk-sharing channel suggests that resources should flow from the low marginal utility country to the high marginal utility country. The relative intensity of these two channels depends on whether the economy is affected by shortor long-run shocks.

With respect to short-run shocks, the productivity channel always dominates, i.e., the most productive country receives resources from abroad and invests more. This result holds both in the BKK model with standard preferences and in our setting with recursive preferences. Hence our ability to turn the quantity anomaly into a general equilibrium regularity depends on long-run shocks. Specifically, with time additive preferences, the country that is expected to be more productive for the long-run receives a net inflow of investment, as in the case of short-run shocks. With recursive 
preferences, instead, the opposite is true as the risk-sharing channel dominates over the productivity channel.

To better understand this result, assume that the home country receives good news for the long-run while the foreign country receives no shock. Upon impact, the marginal utility of the home country drops substantially because even small positive news for the long-run can produce a substantial increase in domestic continuation utility. In order to equalize marginal utility across domestic and foreign agents (risk-sharing channel), resources have to flow abroad so that foreign consumption can immediately increase. Because of the lower home-bias in investment, the most efficient way to help the foreign country is to export investment goods. As investment goods of the home country can be used more effectively to boost foreign investment, more foreign goods can be freed up to support foreign consumption.

Our empirical analysis is consistent with these theoretical findings. We follow Colacito and Croce (2011) and Bansal et al. (2010) in identifying short- and long-run innovations to productivity by regressing Solow residuals on a set of predictive variables, ranging from asset prices to quantities. These estimations are performed under the retained assumption that the United States is the home country, and consider a set of foreign countries which includes Canada, France, Germany, Italy, Japan, the United Kingdom, and a Rest of the World aggregate that features G-7 countries with the exclusion of the U.S.

Our empirical results confirm the model's prediction that investment and net exports of investment respond with opposite signs to short- and long-run innovations. Indeed all the signs and the magnitudes of the estimated coefficients are always in line with the prediction of the model. For this reason, we regard our model as a noticeable step forward in the international macroeconomics literature. By unveiling a new long-run risk-based trading channel that is consistent with the data, we propose a novel way to think about both international capital flows and production frontier dynamics. This framework may be of great interest for both long-term fiscal and monetary policy considerations.

In the next section we discuss further related literature. In sections 3 and 4 we present our model and our equilibrium conditions, respectively. In section 5 we discuss our results. Section 6 summarizes our empirical evidence and section 7 con- 
cludes.

\section{Further Literature Discussion}

Using the recursive methods in Colacito and Croce (2012), Tretvoll (2012) is the first to study a production economy with capital accumulation and recursive preferences. We differ from Tretvoll (2012) in several respects. First of all, Tretvoll (2012) does not consider long-run shocks, which are instead the main element of both our theoretical and empirical investigation. Our paper is therefore the first one to highlight the existence of a relevant long-run risk-based investment channel.

Second, Tretvoll (2012) considers neither the EGG nor the ACL observations about investment composition and capital accumulation. For this reason, the quantitative performance of our model represents a substantial improvement relative to the existing literature. Third, Tretvoll (2012) uses a calibration in the spirit of the RBC literature with an IES smaller than 1 and a risk aversion of 100 . We adopt a calibration in the spirit of Bansal and Yaron (2004), with a relative risk aversion of 10 and an IES slightly larger than 1.

We use Greenwood et al. (1988) preferences to bundle consumption and leisure in order to address Raffo (2008)'s critique about the sources of countercyclicality of the net exports. We also use Erceg et al. (2008)'s evidence on the composition of imports and exports to highlight the relevance of the long-run recursive risk sharing channel. We differ from both Erceg et al. (2008) and Raffo (2008) because of our long-run risk approach with recursive preferences. Ai et al. (2012) do not address international dynamics. Colacito and Croce (2012) address international dynamics abstracting away from production activity and international investment flows.

Several studies have highlighted the role of real and financial frictions (among others, see Stockman and Tesar (1995), Baxter and Crucini (1995), Kehoe and Perri (2002), Heathcote and Perri (2004), Bai and Zhang (2010), Petrosky-Nadeau (2011), Alessandria et al. (2011)). Our analysis is different for the emphasis on risk and recursive preferences in the context of a frictionless economy.

From an empirical point of view, we expand the methodology used in previous work 
(Colacito and Croce 2011) to show that country-specific long-run shocks have a well identified negative impact on contemporaneous investment flows, consistent with our model. Our findings are broadly consistent with the international empirical investigation of Kose et al. (2003, 2008), as we do find evidence of a highly correlated economic productivity factor across G-7 countries in our post-1970 sample. From a finance perspective, we provide a productivity-based general equilibrium explanation of the findings in Lustig and Verdelhan (2007), Colacito (2008), Lustig et al. (2011a, b), and Bansal and Shaliastovich (2010).

\section{The Economy}

We study a two-country and two-good economy similar to Backus et al. (1994). We first describe the technology used to produce consumption goods and the role played by recursive preferences. We then turn our attention to the international production structure. In what follows, we denote foreign variables by “*” and use small letters for $\log$ units, i.e., $x_{t}=\log X_{t}$.

Consumption aggregate. Let $\left\{X_{t}, Y_{t}\right\}$ and $\left\{X_{t}^{*}, Y_{t}^{*}\right\}$ denote the time $t$ consumption of good $X$ and $Y$ in the home and foreign country, respectively. The consumption aggregates in our two countries take the following CES form:

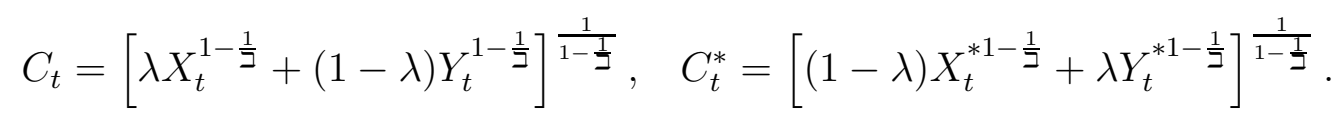

We assume that the home (foreign) country produces good $X(Y)$ and set $\lambda>1 / 2$ to build consumption home bias into our model. This is a standard assumption in the international macro-finance literature (see Lewis 2011).

Consumption bundle. The domestic (foreign) country consumes a composite bundle, $\widetilde{C}\left(\widetilde{C}^{*}\right)$, of consumption and leisure. As in Raffo (2008), we adopt Greenwood et al. (1988) (henceforth GHH) preferences to avoid counterfactual adjustments of 
the terms of trade:

$$
\tilde{C}_{t}=C_{t}-\varphi N_{t}^{1+\frac{1}{f}} A_{t-1}, \quad \tilde{C}_{t}^{*}=C_{t}^{*}-\varphi N_{t}^{* 1+\frac{1}{f}} A_{t-1}^{*},
$$

where $N$ and $N^{*}$ denote the share of hours worked, and $A$ and $A^{*}$ measure both the productivity levels in the home and foreign country and their standards of living. This specification of the $\mathrm{GHH}$ preferences guarantees balanced growth.

Preferences. In each country, the representative agent has Epstein and Zin (1989) recursive preferences. For the home country, we have the following expression:

$$
U_{t}=\left[(1-\delta) \cdot \widetilde{C}_{t}^{1-1 / \psi}+\delta E_{t}\left[U_{t+1}^{1-\gamma}\right]^{\frac{1-1 / \psi}{1-\gamma}}\right]^{\frac{1}{1-1 / \psi}}
$$

The preferences of the foreign country are defined in the same manner over the consumption bundle $\widetilde{C}_{t}^{*}$. The coefficients $\gamma$ and $\psi$ measure the relative risk aversion (RRA) and the intertemporal elasticity of substitution (IES), respectively. We assume that the two countries have the same RRA and IES, as well as the same subjective discount factor.

With these preferences, agents are risk averse in future utility as well as future consumption. The extent of such utility risk aversion depends on the preference for early resolution of uncertainty measured by $\gamma-1 / \psi>0$. To better highlight this feature of the preferences, we focus on the ordinally equivalent transformation

$$
V_{t}=\frac{U_{t}^{1-1 / \psi}}{1-1 / \psi}
$$

and obtain the approximation

$$
V_{t} \approx(1-\delta) \frac{\widetilde{C}_{t}^{1-1 / \psi}}{1-1 / \psi}+\delta E_{t}\left[V_{t+1}\right]-(\gamma-1 / \psi) \operatorname{Var}_{t}\left[V_{t+1}\right] \kappa_{t},
$$

where $\kappa_{t} \equiv \frac{\delta}{2 E_{t}\left[U_{t}^{1-1 / \psi}\right]}>0$. When $\gamma=1 / \psi$, the agent is utility-risk neutral and preferences collapse to the standard time-additive case. When the agent prefers early resolution of uncertainty, i.e., $\gamma>1 / \psi$, uncertainty about continuation utility reduces welfare and generates an incentive to trade off future expected utility, $E_{t}\left[V_{t+1}\right]$, for 
future utility risk, $\operatorname{Var}_{t}\left[V_{t+1}\right]$. This trade-off drives international consumption and investment flows and it represents one of the most important element of our analysis. Our study is the first to fully characterize trade with Epstein and Zin (1989) preferences in production economy with long-run shocks. ${ }^{1}$

Since there is a one-to-one mapping between utility, $U_{t}$, and lifetime wealth, i.e., the value of a perpetual claim to consumption, the optimal risk-sharing scheme can also be interpreted in terms of mean-variance trade-off of wealth. For this reason, in what follows we will use the terms "wealth" and "continuation utility" interchangeably.

Aggregate Productivity. We model productivity growth in the spirit of the longrun risk literature. Specifically, we introduce country-specific long-run productivity components (Croce 2008), $z$ and $z^{*}$, and assume that the domestic and foreign productivity processes, $A$ and $A^{*}$, are co-integrated (Colacito and Croce 2012):

$$
\begin{aligned}
\log A_{t} & =\mu+\log A_{t-1}+z_{t-1}+\tau \cdot\left(\log A_{t-1}-\log A_{t-1}^{*}\right)+\varepsilon_{a, t} \\
\log A_{t}^{*} & =\mu+\log A_{t-1}+z_{t-1}^{*}-\tau \cdot\left(\log A_{t-1}-\log A_{t-1}^{*}\right)+\varepsilon_{a, t}^{*} \\
z_{t} & =\rho z_{t-1}+\varepsilon_{z, t} \\
z_{t}^{*} & =\rho z_{t-1}^{*}+\varepsilon_{z, t}^{*} .
\end{aligned}
$$

Consistent with previous literature, $\tau \in(0,1)$ is calibrated to a small number to generate moderate cointegration. In contrast, the autoregressive coefficient $\rho$ is calibrated to a high number to capture low frequency productivity adjustments.

Throughout the paper, we refer to $\varepsilon_{z, t}$ and $\varepsilon_{z, t}^{*}$ as long-run shocks, due to their longlasting impact on the growth rates of the two goods. Similarly, we call $\varepsilon_{a, t}$ and $\varepsilon_{a, t}^{*}$ short-run shocks. Shocks are jointly log-normally distributed:

$$
\xi_{t} \equiv\left[\begin{array}{llll}
\varepsilon_{z, t} & \varepsilon_{z, t}^{*} & \varepsilon_{a, t} & \varepsilon_{a, t}^{*}
\end{array}\right] \sim \quad \text { i.i.d.N }(\mathbf{0}, \Sigma),
$$

\footnotetext{
${ }^{1}$ Equation (3) is reported only for explanation purposes. The rest of the analysis is conducted with the preference specification in (2).
} 
where

$$
\Sigma=\left[\begin{array}{cccc}
\sigma_{x}^{2} & \rho_{l r r} \sigma_{x}^{2} & 0 & 0 \\
\rho_{l r} \sigma_{x}^{2} & \sigma_{x}^{2} & 0 & 0 \\
0 & 0 & \sigma^{2} & \rho_{s r r} \sigma^{2} \\
0 & 0 & \rho_{s r r} \sigma^{2} & \sigma^{2}
\end{array}\right]
$$

Our economy features a large correlation of long-run components (large $\rho_{l r r}$ ) and a low correlation of short-run shocks (low $\rho_{s r r}$ ) across countries in the spirit of Backus et al. (1994), and Colacito and Croce (2011, 2012).

Production Function and Resource Constraints. In each country, output is a Cobb-Douglas aggregation of country-specific capital and labor. Output can be used for consumption or investment:

$$
\begin{aligned}
X_{t}^{\text {Tot }} & =K_{t}^{\alpha}\left(A_{t} N_{t}\right)^{1-\alpha}=X_{t}+X_{t}^{*}+I_{x, t}+I_{y, t} \\
Y_{t}^{\text {Tot }} & =K_{t}^{* \alpha}\left(A_{t}^{*} N_{t}^{*}\right)^{1-\alpha}=Y_{t}^{*}+Y_{t}+I_{y, t}^{*}+I_{x, t}^{*} .
\end{aligned}
$$

From a home (foreign) country perspective, $I_{x, t}\left(I_{y, t}^{*}\right)$ measures real local investment, while $I_{y, t}\left(I_{x, t}^{*}\right)$ measures investment abroad. Even though capital stocks and labor services are country-specific, agents can trade both consumption and investment goods without any friction in every period and state of the world. We link our resource constraints to quantities recorded in the national accounts as follows:

$$
\begin{aligned}
& X_{t}^{\text {Tot }}=\underbrace{\left(X_{t}+P_{t} Y_{t}\right)}_{C_{m, t}}+\underbrace{\left(I_{x, t}+P_{t} I_{x, t}^{*}\right)}_{I_{m, t}}+\underbrace{\left(X_{t}^{*}+I_{y, t}\right)}_{E x p_{m, t}}-\underbrace{P_{t}\left(Y_{t}^{*}+I_{x, t}^{*}\right)}_{I m p_{m, t}} \\
& Y_{t}^{T o t}=\underbrace{\left(Y_{t}^{*}+X_{t}^{*} / P_{t}\right)}_{C_{m, t}^{*}}+\underbrace{\left(Y_{t}+I_{x, t}^{*}\right)}_{I_{m, t}^{*}\left(I_{y, t}^{*}+I_{y, t} / P_{t}\right)}-\underbrace{\left(X_{t}^{*}+I_{y, t}\right) / P_{t}}_{E x p_{m, t}^{*}},
\end{aligned}
$$

where $P_{t}=\frac{1-\lambda}{\lambda}\left(\frac{X_{t}}{Y_{t}}\right)^{\frac{1}{2}}$ denotes the terms of trade and the subscript $m$ indicates that we are referring to accounting aggregates measured in local units. ${ }^{2}$

${ }^{2}$ This is done to distinguish, for example, $C_{m, t}=X_{t}+P_{t} Y_{t}$ from $C_{t}=\left[\lambda X_{t}^{1-\frac{1}{I}}+(1-\lambda) Y_{t}^{1-\frac{1}{2}}\right]^{1 /\left(1-\frac{1}{2}\right)}$. 
Capital Accumulation. In each country, the stock of physical capital is a productivitybased weighted average of new and old investments. Ai et al. (2012) document that exposure to aggregate productivity risk is increasing with investment age. Specifically, they show that the exposure of newly created capital vintages, $\phi_{0}$, is statistically zero and that the exposure of older vintages is about one. Working with a continuum of overlapping vintages of capital, they prove that aggregate physical capital follows the dynamics reported below:

$$
K_{t+1}=\left(1-\delta_{k}\right) K_{t}+\varpi_{t+1} G_{t}, \quad K_{t+1}^{*}=\left(1-\delta_{k}\right) K_{t}^{*}+\varpi_{t+1}^{*} G_{t}^{*},
$$

where $\delta_{k}$ takes into account depreciation; $G_{t}$ and $G_{t}^{*}$ measure the mass of the new vintage of capital; and $K_{t}$ and $K_{t}^{*}$ measure the total mass of all the other older vintages of capital. The processes $\omega_{t}$ and $\omega_{t}^{*}$ take into account productivity differences across new and old vintages and are endogenously specified as follows:

$$
\varpi_{t+1}=e^{-\left(1-\phi_{0}\right) \frac{1-\alpha}{\alpha}\left(\Delta a_{t+1}-\mu\right)}, \quad \varpi_{t+1}^{*}=e^{-\left(1-\phi_{0}\right) \frac{1-\alpha}{\alpha}\left(\Delta a_{t+1}^{*}-\mu\right)} .
$$

When $\phi_{0}=0$, these processes are a negative transformation of the productivity shocks; i.e., good news to productivity of existing capital is relatively bad news for the new vintages of capital. The reason is that new vintages do not immediately pick up the productivity gain and hence they contribute relatively less to the formation of aggregate capital. When $\phi_{0}=1$, heterogeneity in productivity exposure is shut down and capital accumulation evolves as in the BKK setting.

We consider capital vintage heterogonous exposure to productivity risk because it is relevant to improve the asset pricing performance of production-based long-run risk models. Specifically, this channel allows the model to simultaneously produce sizeable fluctuations in investment and marginal value of capital (Ai et al. 2012).

New Capital Formation. New capital is a CES aggregation of domestic and foreign goods:

$$
G_{t}=\left[\nu I_{x, t}^{1-\frac{1}{\xi}}+(1-\nu) I_{x, t}^{* 1-\frac{1}{\xi}}\right]^{\frac{1}{1-\frac{1}{\xi}}}, \quad G_{t}^{*}=\left[(1-\nu) I_{y, t}^{1-\frac{1}{\xi}}+\nu I_{y, t}^{* 1-\frac{1}{\xi}}\right]^{\frac{1}{1-\frac{1}{\xi}}}
$$


When $\nu=\lambda$ and $\xi=\beth$, our technology for the production of new capital is identical to BKK. Erceg et al. (2008), however, point out that under this restriction the share of imported consumption goods is identical to the share of imported investment goods. This is counterfactual, since a substantial share of the imports in the U.S. are related to capital goods, as opposed to consumption goods.

\section{Risk-sharing Rules and Asset Prices}

We assume that markets are complete both domestically and internationally. This implies that the allocation of the competitive equilibrium can be found by solving the Pareto problem associated to our economy. Prices can then be recovered using the planner's shadow valuations. We start with the equilibrium conditions for the consumption goods and then show the optimal investment rules.

Consumption allocations. The optimal allocation of the two goods devoted to consumption can be characterized using the following first order necessary conditions:

$$
\begin{aligned}
& S_{t} \cdot \frac{\partial C_{t}}{\partial X_{t}} \cdot \frac{1}{C_{t}}=\frac{\partial C_{t}^{*}}{\partial X_{t}^{*}} \cdot \frac{1}{C_{t}^{*}} \\
& S_{t} \cdot \frac{\partial C_{t}}{\partial Y_{t}} \cdot \frac{1}{C_{t}}=\frac{\partial C_{t}^{*}}{\partial Y_{t}^{*}} \cdot \frac{1}{C_{t}^{*}},
\end{aligned}
$$

where $S_{t}$ is the ratio of the pseudo-Pareto weight of the home and foreign country, respectively. The dynamics of the additional state variable $S_{t}$ are given by the process:

$$
S_{t}=S_{t-1} \frac{M_{t}}{M_{t}^{*}} \frac{e^{\Delta c_{t}}}{e^{\Delta c_{t}^{*}}},
$$

where $M_{t}$ denotes the home stochastic discount factor expressed in units of the local consumption aggregate, $C_{t}$,

$$
M_{t+1}=\beta\left(\frac{\widetilde{C}_{t+1}}{\widetilde{C}_{t}}\right)^{-\frac{1}{\psi}}\left(\frac{U_{t+1}}{E_{t}\left[U_{t+1}^{1-\gamma}\right]^{\frac{1}{1-\gamma}}}\right)^{\frac{1}{\psi}-\gamma},
$$

and $M_{t}^{*}$ takes the same form but refers to the foreign country. 
Asset prices. The stochastic discount factors in local output units can be specified as follows:

$$
\begin{aligned}
& M_{t+1}^{X}=\left(\frac{X_{t}}{X_{t+1}} \frac{C_{t+1}}{C_{t}}\right)^{\frac{1}{\underline{I}}} M_{t+1}, \\
& M_{t+1}^{Y}=\left(\frac{Y_{t}^{*}}{Y_{t+1}^{*}} \frac{C_{t+1}^{*}}{C_{t}^{*}}\right)^{\frac{1}{\underline{I}}} M_{t+1}^{*} .
\end{aligned}
$$

Let $Q_{k, t}$ and $P_{k, t}$ denote the ex- and cum-dividends price of domestic capital expressed in local output units, respectively. International capital prices satisfy the following equations:

$$
\begin{array}{rlrl}
P_{k, t}=\alpha \frac{X_{t}^{T o t}}{K_{t}}+(1-\delta) Q_{k, t}, & P_{k, t}^{*} & =\alpha \frac{Y_{t}^{T o t}}{K_{t}^{*}}+(1-\delta) Q_{k, t}^{*} \\
Q_{k, t}=E_{t}\left[M_{t+1}^{X} P_{k, t+1}\right], & Q_{k, t}^{*}=E_{t}\left[M_{t+1}^{Y} P_{k, t+1}^{*}\right] .
\end{array}
$$

The returns of capital in the domestic and foreign country are:

$$
R_{k, t+1}=\frac{P_{k, t+1}}{Q_{k, t}}, \quad R_{k, t+1}^{*}=\frac{P_{k, t+1}^{*}}{Q_{k, t}^{*}}
$$

and the real risk-free rates are computed as follows:

$$
1 / R_{f, t}=E_{t}\left[M_{t+1}^{X}\right], \quad 1 / R_{f, t}^{*}=E_{t}\left[M_{t+1}^{Y}\right]
$$

Since markets are complete, the log-growth of the real exchange rate in consumption units is:

$$
\Delta e_{t+1}=m_{t+1}-m_{t+1}^{*}
$$

Optimal Investment. Similarly to Ai et al. (2012), optimal investment of each agent in its own country satisfies the following conditions:

$$
\frac{1}{\nu}\left(\frac{I_{x, t}}{G_{t}}\right)^{\frac{1}{\xi}}=E_{t}\left[M_{t+1}^{X} P_{k, t+1} e^{\varpi_{t+1}}\right], \quad \frac{1}{\nu}\left(\frac{I_{y, t}^{*}}{G_{t}^{*}}\right)^{\frac{1}{\xi}}=E_{t}\left[M_{t+1}^{Y} P_{k, t+1}^{*} e^{\varpi_{t+1}^{*}}\right] .
$$

Heterogenous exposure to productivity shocks creates a stochastic wedge between the price of new and old capital vintages $\left(\varpi_{t+1}\right.$ and $\left.\varpi_{t+1}^{*}\right)$ which is not known when the 


\section{TABLE 1: Main Components of Our Economy}

\begin{tabular}{lccccccc}
\hline \hline Model: & (1) & (2) & (3) & (4) & (5) & (5b) & $(6)$ \\
\hline Long-run risk & & $\checkmark$ & $\checkmark$ & $\checkmark$ & $\checkmark$ & $\checkmark$ & $\checkmark$ \\
High RRA & & & $\checkmark$ & $\checkmark$ & $\checkmark$ & $\checkmark$ & $\checkmark$ \\
$\begin{array}{l}\text { High IES } \\
\text { Milder Investment home bias }\end{array}$ & & & & $\checkmark$ & $\checkmark$ & $\checkmark$ & $\checkmark$ \\
$\begin{array}{l}\text { Heterogenous productivity } \\
\text { of Vintage Capital }\end{array}$ & & & & & $\checkmark$ & & $\checkmark$ \\
\hline
\end{tabular}

Notes - This table summarizes the main components active in each of our models. All parameter values are reported in Table 2. Model (1) refers to the original BKK economy. Model (6) is our benchmark.

investment decision is made at time $t$. For this reason, the agent equalizes the known marginal cost of capital $\left(\partial G / \partial I_{x}\right.$ and $\left.\partial G^{*} / \partial I_{y}^{*}\right)$ to the expected discounted present value of a marginal unit of new capital adjusted by its relative productivity.

In an analogous way, investments abroad are determined by the following no-arbitrage equations:

$$
\frac{1}{1-\nu}\left(\frac{I_{y, t}}{G_{t}^{*}}\right)^{\frac{1}{\xi}}=E_{t}\left[M_{t+1}^{X}\left(P_{k, t+1}^{*} e^{\varpi_{t+1}^{*}}\right) P_{t+1}\right], \quad \frac{1}{1-\nu}\left(\frac{I_{x, t}^{*}}{G_{t}}\right)^{\frac{1}{\xi}}=E_{t}\left[M_{t+1}^{Y}\left(P_{k, t+1} e^{\varpi_{t+1}}\right) / P_{t+1}\right],
$$

which take into account exchange rate risk through the terms of trade, $P_{t}$, channel.

\section{Inspecting the Mechanism}

In this section we explore the relevance of the key elements of our model. In order to do so, we start from a pure BKK economy and move toward our benchmark model by adding one modification at a time. We do so by comparing six models whose key elements are summarized in Table 1. Our six calibrations are detailed in Table 2.

Model (1) is a pure BKK economy with cointegrated productivity processes. In model (2) we add long-run risk to the standard BKK model and show that it plays no significant role with standard preferences. Models (3) and (4) highlight the relevance of higher risk aversion and higher IES, respectively. In the last three calibrations, 
we modify the technology structure and show that when the EGG and the ACL observations are combined together, the response of international investment flows to long-run news changes radically.

\subsection{From BKK to EZ-BKK}

By comparing the first two columns of Table 3, it is possible to see that long-run risk does little in an economy with standard preferences and BKK technology. Except for the increase in both the volatility and the cross-country correlation of the interest rates, nothing else changes in a significant way.

In Figure 1, we show the response of macroeconomic quantities to both short-run (left panels) and long-run shocks (right panels) across models (2), (3) and (4). First of all, we note that moving from standard time additive preferences to recursive preferences with higher RRA and IES alters only marginally the response of quantities to short-run shocks. In economies with just short-run uncertainty, therefore, recursive preferences alone are bound to fail in explaining the data as much as standard preferences.

When we turn our attention to long-run news, in contrast, the responses look quite different across models over the first few periods. Specifically, when the IES is set to $1 / 2$ (models (2) and (3)), the agent has a strong incentive to consume more upon the realization of good long-run news. This is a reflection of the fact that the income effect dominates the substitution effect: as good long-run news increases wealth, the agent reduces savings and investment. In contrast, when the IES is set above unity the substitution effect becomes stronger and both consumption and investment growth adjust by a moderate amount.

Another difference across models (2) and (4) is related to the response of the net exports-output ratio to a positive long-run shock. When the IES is set to $1 / 2$, the home country is a net importer; i.e., it finances part of its consumption through for-

eign resources. When, instead, the IES is set to 1.1 the home country becomes a net exporter. In the first case, resources flow from the country with relatively poorer growth prospects to the country that is expected to be most productive for the longrun. In the second case, instead, resources flow away from the most productive coun- 
TABLE 2: Calibrated Parameter Values

\begin{tabular}{|c|c|c|c|c|c|c|c|c|}
\hline Model: & & $(1)$ & $(2)$ & $(3)$ & $(4)$ & $(5)$ & $(5 \mathrm{~b})$ & $(6)$ \\
\hline Subjective discount factor & $\beta$ & 0.985 & 0.985 & 0.985 & 0.985 & 0.985 & 0.985 & 0.9873 \\
\hline Risk aversion & $\gamma$ & 2 & 2 & 10 & 10 & 10 & 10 & 10 \\
\hline IES & $\psi$ & 0.5 & 0.5 & 0.5 & 1.1 & 1.1 & 1.1 & 1.1 \\
\hline Consumption home bias & $\lambda$ & 0.76 & 0.76 & 0.76 & 0.76 & 0.76 & 0.97 & 0.97 \\
\hline Consumption-bundle elasticity & $\beth$ & 1.5 & 1.5 & 1.5 & 1.5 & 1.5 & 1 & 1 \\
\hline Consumption-labor elasticity & $f$ & 1 & 1 & 1 & 1 & 1 & 1 & 1 \\
\hline Capital Income Share & $\alpha$ & 0.36 & 0.36 & 0.36 & 0.36 & 0.3 & 0.3 & 0.3 \\
\hline Depreciation rate of capital & $\delta$ & 0.1 & 0.1 & 0.1 & 0.1 & 0.06 & 0.06 & 0.06 \\
\hline Investment home bias & $\nu$ & 0.76 & 0.76 & 0.76 & 0.76 & 0.76 & 0.53 & 0.57 \\
\hline Investment-bundle elasticity & $\xi$ & 1.5 & 1.5 & 1.5 & 1.5 & 1.5 & 1 & 1 \\
\hline Exposure of young vintages & $\phi_{0}$ & 1 & 1 & 1 & 1 & 0 & 1 & 0 \\
\hline Long run mean of productivity & $\mu$ & 0.02 & 0.02 & 0.02 & 0.02 & 0.02 & 0.02 & 0.02 \\
\hline Persistence of long run shock & $\rho$ & 0.9859 & 0.9859 & 0.9859 & 0.9859 & 0.9859 & 0.9859 & 0.9859 \\
\hline Co-integration parameter & $\tau$ & $5 \mathrm{E}-05$ & 5E-05 & $5 \mathrm{E}-05$ & $5 \mathrm{E}-05$ & $5 \mathrm{E}-05$ & $5 \mathrm{E}-05$ & $5 \mathrm{E}-05$ \\
\hline Short-run shock vol. & $\sigma$ & 0.027 & 0.027 & 0.027 & 0.027 & 0.027 & 0.027 & 0.027 \\
\hline Long-run shock vol. & $\sigma_{x}$ & 0 & $.15 \sigma$ & $.15 \sigma$ & $.15 \sigma$ & $.15 \sigma$ & $.15 \sigma$ & $.15 \sigma$ \\
\hline Short-run shocks correlation & $\rho_{\text {srr }}$ & 0 & 0.027 & 0.027 & 0.027 & 0.027 & 0.027 & 0.027 \\
\hline Long-run shocks correlation & $\rho_{l r r}$ & - & 0.85 & 0.85 & 0.85 & 0.85 & 0.85 & 0.85 \\
\hline
\end{tabular}

Notes - This table reports the parameter values used for our calibrations. All models are calibrated at an annual frequency. Model (1) refers to the original BKK economy. Model (6) is our benchmark. 
TABLE 3: From BKK to EZ-BKK

\begin{tabular}{|c|c|c|c|c|c|}
\hline Model: & (1) & 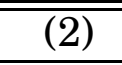 & $\overline{~(3)}$ & $\overline{(4)}$ & Data \\
\hline \multicolumn{6}{|c|}{ Quantities } \\
\hline$\overline{\mathrm{E}}\left[I_{m} / X^{\mathrm{Tot}}\right]$ & 27.60 & 28.34 & 30.52 & 35.21 & 20.13 \\
\hline $\mathrm{E}\left[\left(I_{u}^{*}+Y\right) P / X^{T o t}\right]$ & 15.22 & 15.28 & 15.39 & 15.25 & 10.90 \\
\hline $\mathrm{E}\left[I_{y}^{*} P / I_{m}\right]$ & 15.21 & 15.16 & 15.18 & 15.18 & 40.00 \\
\hline $\mathrm{E}\left[P \cdot Y / C_{m}\right]$ & 15.22 & 15.29 & 15.32 & 15.28 & 5.00 \\
\hline $\operatorname{vol}\left(\Delta x^{T o t}\right)$ & 2.70 & 3.09 & 3.08 & 3.15 & 3.49 \\
\hline $\operatorname{vo}\left(\Delta c_{m}\right)$ & 2.08 & 2.66 & 2.73 & 2.63 & 2.53 \\
\hline $\operatorname{vol}\left(\Delta i_{m}\right)$ & 7.85 & 8.27 & 8.08 & 7.16 & 16.40 \\
\hline $\operatorname{vol}(\Delta n)$ & 2.20 & 2.24 & 2.25 & 2.24 & 2.07 \\
\hline $\operatorname{corr}(\Delta c, \Delta n)$ & 0.77 & 0.59 & 0.58 & 0.62 & 0.28 \\
\hline $\operatorname{corr}\left(\Delta c_{m}, \Delta i_{m}\right)$ & 0.80 & 0.64 & 0.56 & 0.77 & 0.39 \\
\hline $\operatorname{vol}\left(N X / X^{T o t}\right)$ & 1.08 & 1.38 & 1.35 & 1.51 & 2.40 \\
\hline $\operatorname{corr}\left(\Delta N X / X^{T o t}, \Delta x^{T o t}\right)$ & -0.64 & -0.56 & -0.56 & -0.56 & -0.27 \\
\hline $\operatorname{corr}\left(\Delta N X Q / X^{T o t}, \Delta x^{T o t}\right)$ & -0.61 & -0.51 & -0.51 & -0.53 & 0.00 \\
\hline$\overline{\operatorname{corr}\left(\Delta x^{T o t}, \Delta y^{T o t}\right)}$ & 0.04 & 0.21 & 0.20 & 0.23 & 0.41 \\
\hline $\operatorname{corr}\left(\Delta c_{m}, \Delta c_{m}^{*}\right)$ & 0.25 & 0.44 & 0.48 & 0.41 & 0.55 \\
\hline $\operatorname{corr}\left(\Delta i_{m}, \Delta i_{m}^{*}\right)$ & -0.76 & -0.59 & -0.54 & -0.65 & 0.53 \\
\hline $\operatorname{corr}\left(\Delta n, \Delta n^{*}\right)$ & 0.07 & 0.10 & 0.10 & 0.08 & 0.52 \\
\hline \multicolumn{6}{|c|}{ Asset Prices } \\
\hline$\overline{\mathrm{E}}\left[r_{f}\right]$ & 5.48 & 5.27 & 4.27 & 2.21 & 0.86 \\
\hline $\mathrm{E}\left[r_{k}^{e x}\right]$ & 0.01 & 0.01 & 0.08 & 0.08 & 5.71 \\
\hline $\operatorname{Vol}\left[r_{f}\right]$ & 0.38 & 2.44 & 2.59 & 1.29 & 0.97 \\
\hline $\operatorname{Vol}\left[r_{k}^{e x}\right]$ & 1.34 & 1.39 & 1.33 & 1.14 & 20.51 \\
\hline $\operatorname{Vol}(m)$ & 1.90 & 6.76 & 141.90 & 74.34 & - \\
\hline $\operatorname{corr}(m, m *)$ & 0.97 & 0.997 & 0.99 & 0.99 & - \\
\hline $\operatorname{corr}\left(m_{x}, m_{y}\right)$ & 0.86 & 0.99 & 0.99 & 0.99 & - \\
\hline $\operatorname{corr}\left(r_{k}^{e x}, r_{k}^{e x *}\right)$ & -0.29 & -0.34 & -0.35 & -0.34 & - \\
\hline $\operatorname{corr}\left(r_{f}, r_{f}^{*}\right)$ & 0.29 & 0.97 & 0.98 & 0.92 & 65.00 \\
\hline $\operatorname{Vol}(\Delta e)$ & 0.48 & 0.56 & 0.56 & 0.54 & 11.20 \\
\hline
\end{tabular}

Notes - All figures are multiplied by 100, except contemporaneous correlations. Empirical moments are computed using US annual data from 1930 to 2008. International moments are from Raffo (2008). Returns are in log units and are levered using a coefficient of 3 (Garca-Feijo and Jorgensen (2010)). All the parameters are calibrated as in Table 2. The entries for the models are obtained by repetitions of small-sample simulations. 
Home Country Variables
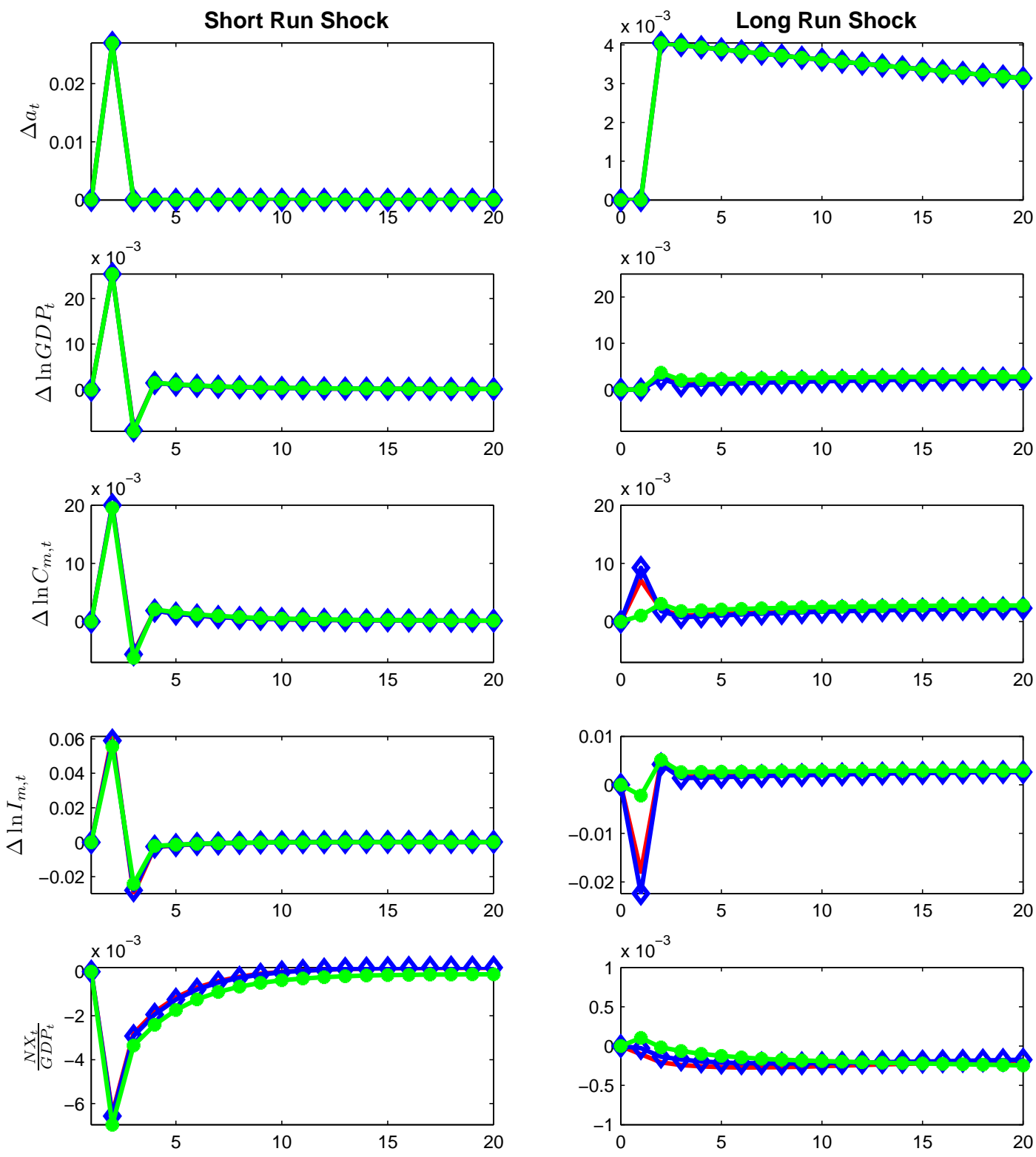

FIG. 1 - Quantities with and without EZ preferences. This figure shows annual log deviations from the steady state. All the parameters are calibrated to the values reported in Table 2. Shocks to the home country productivity, $\epsilon_{a}$ and $\epsilon_{x}$, materialize at time 2. The short-run shock affects only the home country and has a magnitude $\sigma$. The long-run shocks affect both the home country with magnitude $\sigma_{x}$ and the foreign country with magnitude $\rho_{l r r} \sigma_{x}$, where $\rho_{l r r}=\operatorname{corr}\left(\epsilon_{x}, \epsilon_{x}^{*}\right)$. 
Home Country Variables
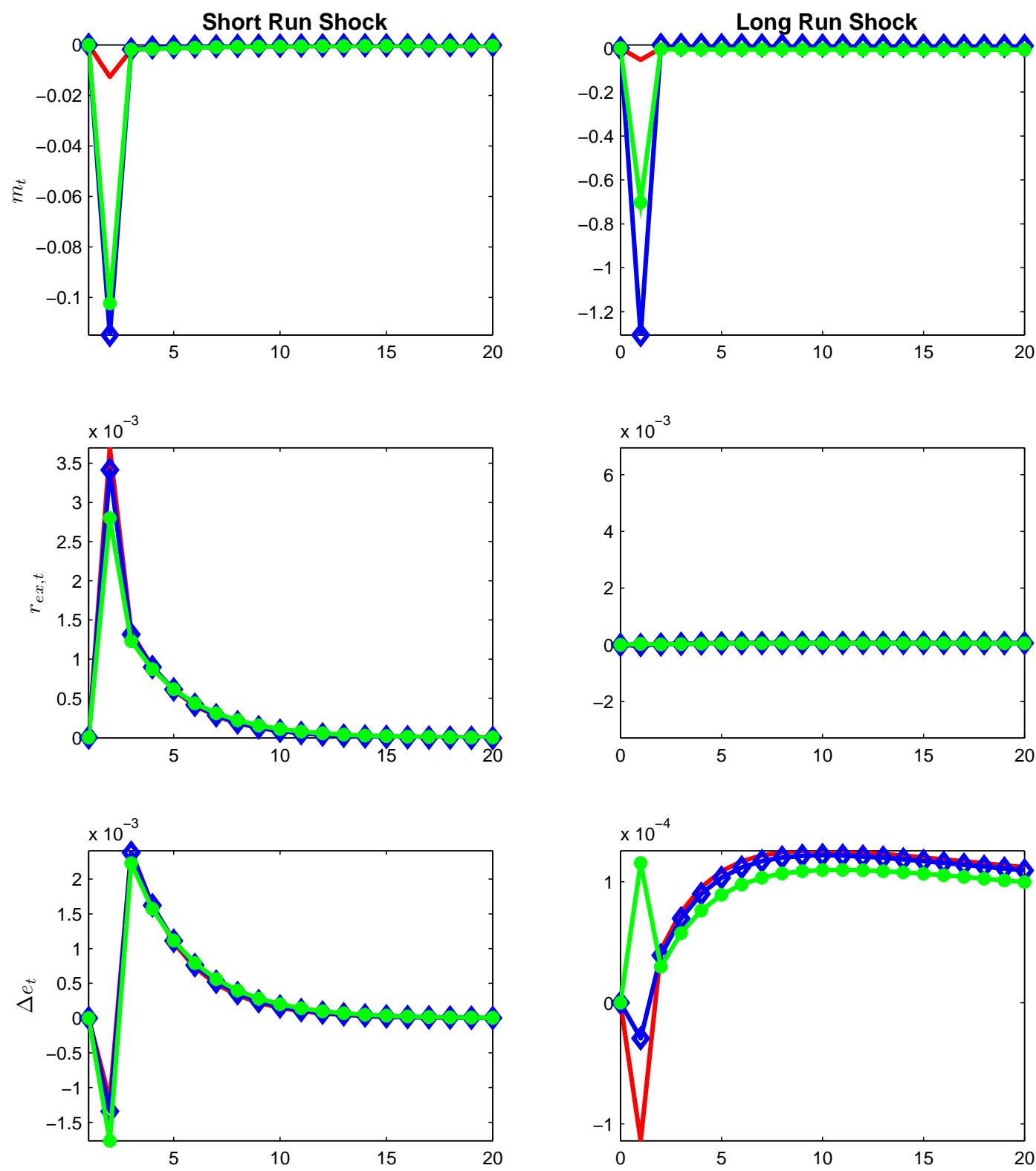

Model (2): BKK with LRR

Model (3): BKK + High RRA

Model (4): EZ-BKK

FIG. 2 - Prices with and without EZ preferences. This figure shows annual log deviations from the steady state. All the parameters are calibrated to the values reported in Table 2. Shocks to the home country productivity, $\epsilon_{a}$ and $\epsilon_{x}$, materialize at time 2. The short-run shock affects only the home country and has a magnitude $\sigma$. The long-run shocks affect both the home country with magnitude $\sigma_{x}$ and the foreign country with magnitude $\rho_{l r r} \sigma_{x}$, where $\rho_{l r r}=\operatorname{corr}\left(\epsilon_{x}, \epsilon_{x}^{*}\right)$. 
try.

This behavior of the net-exports is consistent with the risk-sharing motives highlighted in endowment economy by Colacito and Croce (2012). Agents with high IES and RRA are adverse to utility risk, $\operatorname{Var}_{t}\left(U_{t+1}\right)$, and are willing to give up current resources in exchange for wealth insurance. In this class of models, indeed, if the domestic country receives good news for the long-run, she finds it optimal to give up more resources to the rest of the world in order to have better access to insurance assets in the financial markets and reduce conditional wealth volatility. This finding is relevant in our production economy because it rationalizes the less than perfect correlation between cross-country investment flows and relative productivity. That is, resources do not always immediately flow toward the country that is expected to be the most productive.

These responses of the net exports to long-run shocks explain the different adjustments of the exchange rate highlighted in the bottom right panel of figure 2 . When the IES is set to $1 / 2$, goods flow toward the home country and its currency appreciates. When the IES is set to 1.1, instead, goods flow toward the foreign country and the domestic currency becomes weaker.

Overall, Figure 2 documents that adding recursive preferences to a BKK economy has very little consequences for exchange rates and excess returns. Even though the pricing kernel becomes more volatile because of the higher aversion to utility risk (given by $\gamma-1 / \psi$ ), models (2), (3), and (4) are hard to tell apart. Model (4) features an overly smooth exchange rate and excess returns as in BKK (see Table 3). On the quantities side, model (4) also delivers consumption growth rates that are more cross-country correlated then output growth, which is at odds with the data.

We conclude this section by observing that all models studied so far predict an appreciation of the home currency upon the realization of good short-run news to domestic productivity. This result is very different from that obtained by BKK and is driven by our assumption concerning labor preferences. Indeed, with GHH preferences labor responds only to changes in productivity through the wage channel. This implies that upon the realization of good short-run news to the home country, labor does not increase abroad. Overall, the domestic consumption bundle falls relative to the foreign one due to the drop in leisure, leading to an appreciation of the domestic currency. We 
discuss this point further in section 5.4.

\subsection{From EZ-BKK to our Benchmark model}

In this section we change the technology side of the economy along two key dimensions. First, we take seriously the empirical evidence documented by Erceg et al. (2008) and introduce stronger home-bias in consumption and weaker home-bias in investment. We argue that this is essential to obtain better results on the quantity side. Second, we assume that younger vintages of capital are less exposed to aggregate productivity than older vintages, consistent with Ai et al. (2012). We show that this friction is relevant to capture a significantly higher degree of risk for investment.

\subsubsection{Heterogenous home-bias across consumption and investment}

In Table 4, we report all relevant moments for models (4) through (6). We start our discussion by comparing model (4) and model (5b), i.e., by addressing the role of heterogenous home-bias across consumption and investment. In model (5b), we use the same consumption aggregator adopted by Colacito and Croce (2012) in an exchange economy. We do so to better compare our result to theirs and to highlight the role of production and investment. Specifically, we adopt a simple Cobb-Douglas aggregator $(\beth=1)$ and decrease the share of consumption imports $\left(\mathrm{E}\left[P \cdot Y / C_{m}\right]\right)$ by increasing the consumption home bias $(\lambda=0.97)$, which is consistent with the data.

On the investment side, we retain the BKK assumption that the degree of substitution between foreign and domestic goods is the same across the investment and the consumption sector, i.e., $\xi=\beth$. In this spirit, we set $\xi=1$. To capture openness in trade of investment goods, we adjust $\nu$ and allow the imports of capital goods to increase up to about $40 \%$ of total investment, which is again consistent with the data.

The joint analysis of Table 4 and Figure 3 reveals three important implications. First, by allowing more substitution among capital goods, we obtain a much higher level of investment volatility than in model (4). This is explained by the fact that the $G$ aggregator generates decreasing marginal return of investment similarly to an adjustment cost function. By allowing more cross-country substitution, we reduce the 
TABLE 4: From EZ-BKK to our Benchmark Model

\begin{tabular}{|c|c|c|c|c|c|}
\hline Model: & (4) & (5) & (5b) & (6) & Data \\
\hline \multicolumn{6}{|c|}{ Quantities } \\
\hline$\overline{\mathrm{E}}\left[I_{m} / X^{\mathrm{Tot}}\right]$ & 35.21 & 29.21 & 30.09 & 30.20 & 20.13 \\
\hline $\mathrm{E}\left[\left(I_{y}^{*}+Y\right) P / X^{T o t}\right]$ & 15.25 & 15.33 & 16.33 & 15.22 & 10.90 \\
\hline $\mathrm{E}\left[I_{y}^{*} P / I_{m}\right]$ & 15.18 & 15.19 & 47.31 & 43.49 & 40.00 \\
\hline $\mathrm{E}\left[P \cdot Y / C_{m}\right]$ & 15.28 & 15.29 & 3.00 & 3.00 & 5.00 \\
\hline $\operatorname{vol}\left(\Delta x^{T o t}\right)$ & 3.15 & 3.31 & 3.54 & 3.31 & 3.49 \\
\hline $\operatorname{vo}\left(\Delta c_{m}\right)$ & 2.63 & 2.66 & 3.02 & 2.82 & 2.53 \\
\hline $\operatorname{vol}\left(\Delta i_{m}\right)$ & 7.16 & 9.76 & 27.66 & 25.81 & 16.40 \\
\hline $\operatorname{vol}(\Delta n)$ & 2.24 & 2.38 & 2.46 & 2.37 & 2.07 \\
\hline $\operatorname{corr}(\Delta c, \Delta n)$ & 0.62 & 0.67 & 0.63 & 0.52 & 0.28 \\
\hline $\operatorname{corr}\left(\Delta c_{m}, \Delta i_{m}\right)$ & 0.77 & 0.72 & 0.43 & 0.41 & 0.39 \\
\hline $\operatorname{vol}\left(N X / X^{T o t}\right)$ & 1.51 & 1.78 & 6.67 & 6.98 & 2.40 \\
\hline $\operatorname{corr}\left(\Delta N X / X^{T o t}, \Delta x^{T o t}\right)$ & -0.56 & -0.59 & -0.15 & -0.23 & -0.27 \\
\hline $\operatorname{corr}\left(\Delta N X Q / X^{T o t}, \Delta x^{T o t}\right)$ & -0.53 & -0.56 & -0.06 & -0.14 & 0.00 \\
\hline$\overline{\operatorname{corr}\left(\Delta x^{T o t}, \Delta y^{T o t}\right)}$ & 0.23 & 0.19 & 0.16 & 0.18 & 0.41 \\
\hline $\operatorname{corr}\left(\Delta c_{m}, \Delta c_{m}^{*}\right)$ & 0.41 & 0.40 & 0.04 & 0.13 & 0.55 \\
\hline $\operatorname{corr}\left(\Delta i_{m}, \Delta i_{m}^{*}\right)$ & -0.65 & -0.69 & -0.73 & -0.68 & 0.53 \\
\hline $\operatorname{corr}\left(\Delta n, \Delta n^{*}\right)$ & 0.08 & 0.07 & 0.04 & 0.07 & 0.52 \\
\hline \multicolumn{6}{|c|}{ Asset Prices } \\
\hline$\overline{\mathrm{E}\left[r_{f}\right]}$ & 2.21 & 1.31 & 2.04 & 0.99 & 0.86 \\
\hline $\mathrm{E}\left[r_{k}^{e x}\right]$ & 0.08 & 2.73 & 0.22 & 3.46 & 5.71 \\
\hline $\operatorname{Vol}\left[r_{f}\right]$ & 1.29 & 1.17 & 1.61 & 1.66 & 0.97 \\
\hline $\operatorname{Vol}\left[r_{k}^{e x}\right]$ & 1.14 & 2.80 & 12.11 & 13.99 & 20.51 \\
\hline $\operatorname{Vol}(m)$ & 74.34 & 67.81 & 72.55 & 72.11 & - \\
\hline $\operatorname{corr}(m, m *)$ & 0.99 & 0.99 & 0.99 & 0.99 & - \\
\hline $\operatorname{corr}\left(m_{x}, m_{y}\right)$ & 0.99 & 0.99 & 0.99 & 0.99 & - \\
\hline $\operatorname{corr}\left(r_{k}^{e x}, r_{k}^{e x *}\right)$ & -0.34 & 0.67 & -1.00 & -0.93 & - \\
\hline $\operatorname{corr}\left(r_{f}, r_{f}^{*}\right)$ & 0.92 & 0.90 & 0.21 & 0.17 & 65.00 \\
\hline $\operatorname{Vol}(\Delta e)$ & 0.54 & 0.63 & 8.73 & 10.27 & 11.20 \\
\hline
\end{tabular}

Notes - All figures are multiplied by 100, except contemporaneous correlations. Empirical moments are computed using US annual data from 1930 to 2008. International moments are from Raffo (2008). Returns are in log units and are levered using a coefficient of 3 (Garca-Feijo and Jorgensen (2010)). All the parameters are calibrated as in Table 2. The entries for the models are obtained by repetitions of small-sample simulations. 
Home Country Variables
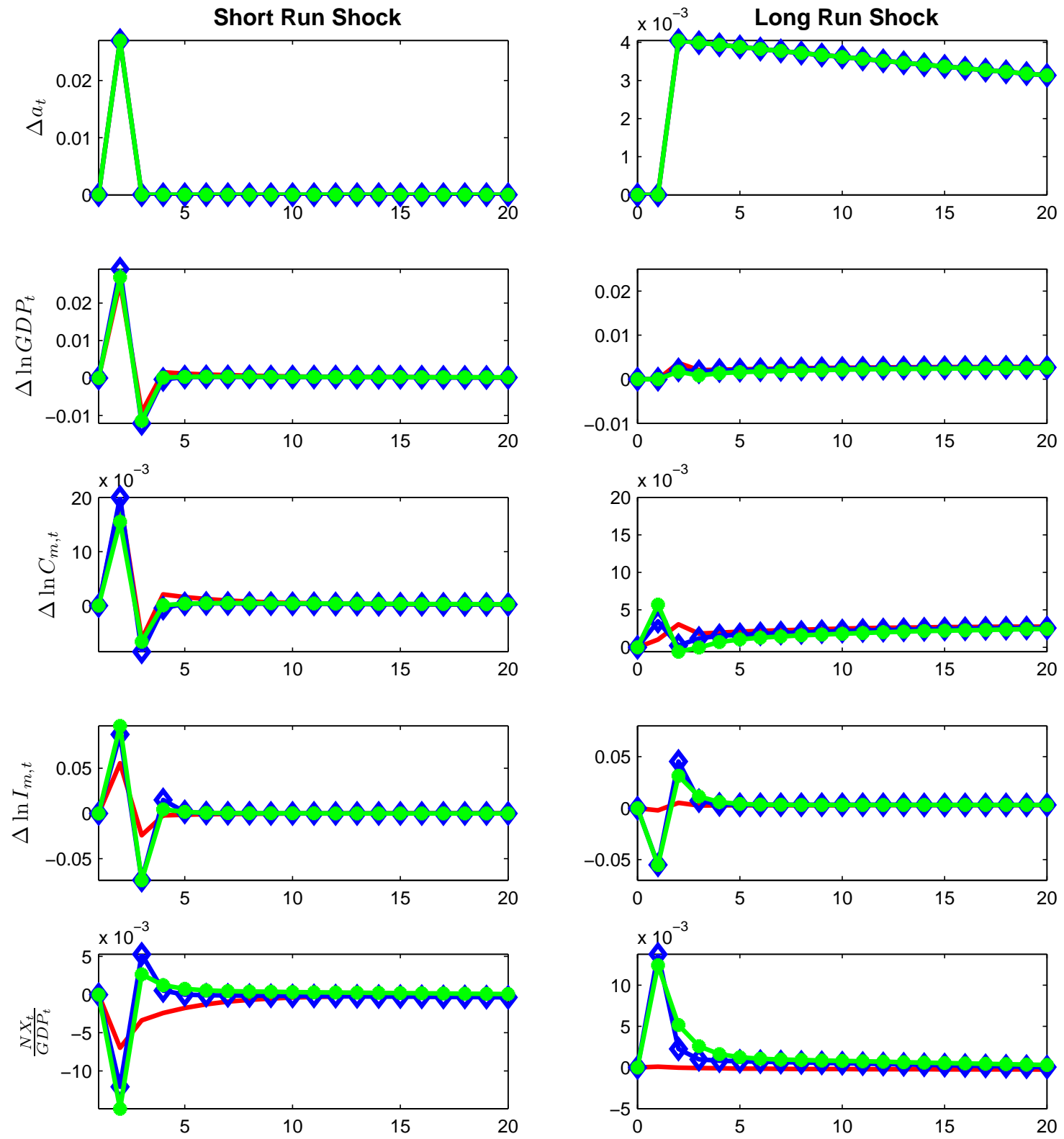

FIG. 3 - Quantities with and without modified investment technology. This figure shows annual log deviations from the steady state. All the parameters are calibrated to the values reported in Table 2 . Shocks to the home country productivity, $\epsilon_{a}$ and $\epsilon_{x}$, materialize at time 2 . The short-run shock affects only the home country and has a magnitude $\sigma$. The long-run shocks affect both the home country with magnitude $\sigma_{x}$ and the foreign country with magnitude $\rho_{l r r} \sigma_{x}$, where $\rho_{l r r}=\operatorname{corr}\left(\epsilon_{x}, \epsilon_{x}^{*}\right)$. 
intensity of the adjustment costs and obtain more sizeable investment fluctuations both within each country and across countries. As a reflection, net exports become more volatile as well. Specifically, the volatility of our net-exports to output ratio is now higher than in the data. This suggests that the volatility of international trade can be significant in this class of models even after adding trading costs or financial frictions. Models with standard preferences are subject to the opposite problem, as they are not able to generate enough trade volatility.

Second, focusing on the two bottom right panels of Figure 3 we can see that in model (5b) the recursive risk sharing motive is amplified. Upon the realizations of good long-run news to domestic productivity, the home country finds it optimal to further decrease aggregate investment, $I_{m}$, in order to export a greater fraction of output. Under model (5b) an even more sizeable flow of resources goes from the country that is expected to be the most productive to the less productive one.

We examine this response from a foreign country perspective. For the foreign economy, receiving more investment goods is very convenient. Because of substitutability, investment in the foreign country, $I_{m}^{*}$, can be supported with home-investment goods, $I_{y}$, even though domestic investment, $I_{y}^{*}$, drops. Under this strategy, more national goods, $Y^{*}$, can be used to support consumption, $C^{*}$. This increase in foreign consumption enable marginal utilities across countries to be equalized according to the risk-sharing channel. With respect to short-run shocks, in contrast, net exports are driven by the productivity channel: more productive countries run negative current accounts as they are net investment receivers.

Third, upon the realization of long-run shocks, investment drops whereas both net exports and consumption growth increase. This helps us better match the data on the co-movements of these variables. Under model (5b), the correlation of the net exports to output ratio and output growth is slightly negative as it is in the data, in contrast to what is observed under model (1). Following Raffo (2008), we construct a measure of net exports under the assumption that the terms of trade are constant, $N X Q$, to test whether our net exports are driven by quantities or relative prices. Our results are driven by the adjustment of international quantities, consistent with U.S. data. The correlation between national consumption and investment growth is moderate as well, which is again consistent with the data. 
Turning our attention to the bottom portion of Table 4 and Figure 4, we make three relevant points about the implications of the EGG observation for asset prices. First, thanks to more sizeable international trade, the terms of trade and hence the exchange rate are much more volatile than in any of the models previously analyzed. Specifically, the growth rate of the exchange rate becomes an order of magnitude larger than before.

Second, thanks to a larger inflow of investment goods, the home country anticipates more domestic capital accumulation upon the realization of positive short-run shocks. This means that the home future utility increases more than in model (4). Since agents are averse to continuation utility-risk in addition to consumption-risk, the marginal utility of the home country falls more than the foreign one. For this reason, under model (5b) short-run shocks produce a depreciation of the home currency, as in standard international RBC models.

Third, looking at domestic capital excess returns and risk-free rates, we can see that lowering the investment home-bias produces very little differences. The EGG observation helps us on the international quantity side, but has no effect on local returns. In the next section we show that introducing heterogenous productivity across capital vintages can improve the performance of the model exactly in this direction.

\subsubsection{Heterogenous Productivity Risk Across Capital Vintages}

In model (5) we add heterogenous productivity risk across capital vintages to model (4), i.e, the EZ-BKK model. In our benchmark model (model (6)), we add the ACL friction to model (5b), i.e., the EZ-BKK economy with lower investment home-bias. By comparing our simulated results in Table 4, we note that the ACL friction is very powerful with asset prices even though it does not seam to significantly affect most of the international quantities. The same conclusion can be obtained by comparing the responses depicted in Figures 3 and 4.

A closer look at international investment flows helps us reveal the impact of this friction on capital dynamics and excess returns. In Figure 5, we plot the investmentoutput share in the home country, keeping constant the terms of trade. The bottom right panel of this figure shows that when long-run shocks materialize, the quantity of 

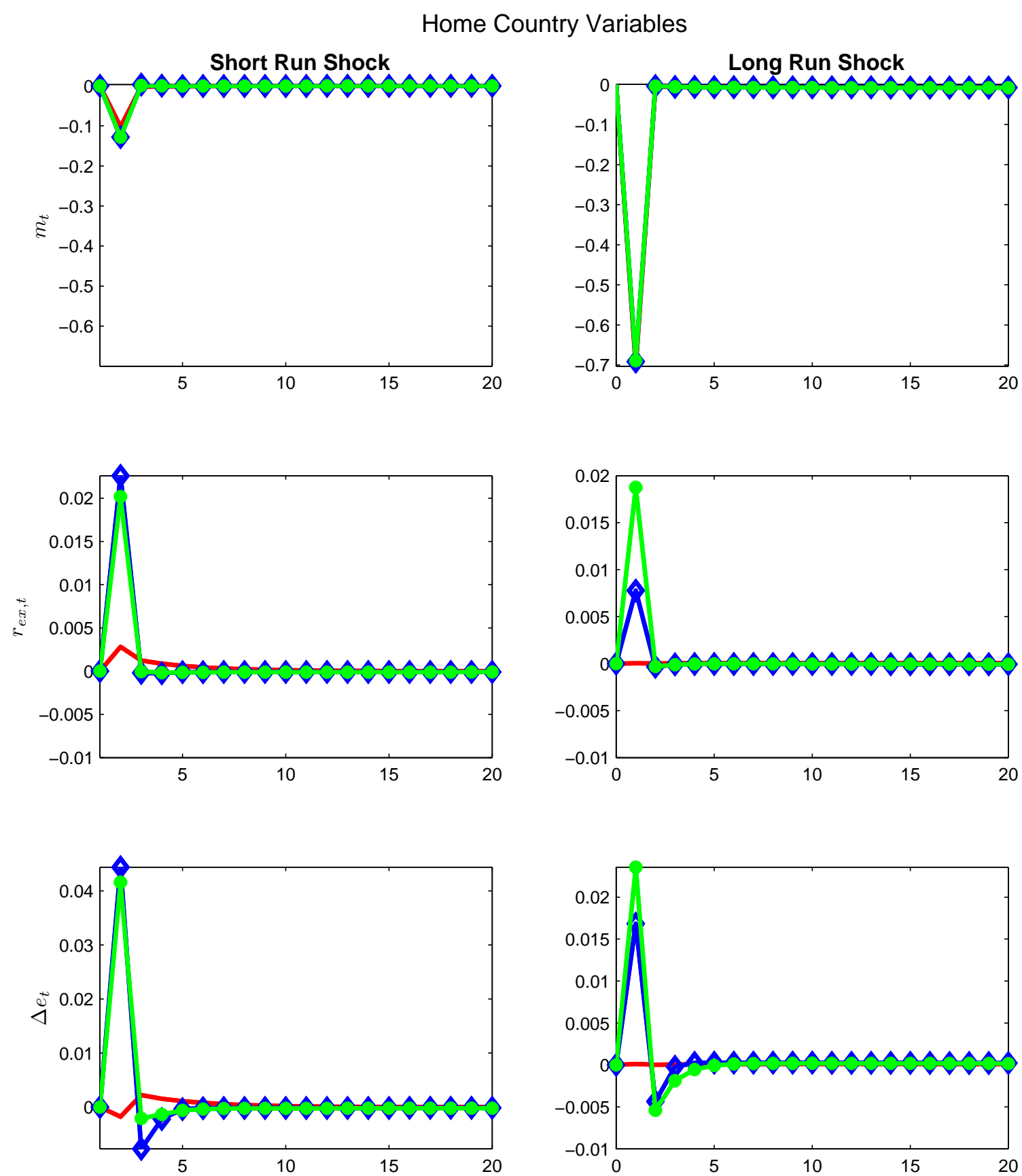

Model (4): EZ-BKK Model (5b): BKK + Heterog. home bias

Model (6): Benchmark

FIG. 4 - Prices with and without modified investment technology. This figure shows annual log deviations from the steady state. All the parameters are calibrated to the values reported in Table 2. Shocks to the home country productivity, $\epsilon_{a}$ and $\epsilon_{x}$, materialize at time 2 . The short-run shock affects only the home country and has a magnitude $\sigma$. The long-run shocks affect both the home country with magnitude $\sigma_{x}$ and the foreign country with magnitude $\rho_{l r r} \sigma_{x}$, where $\rho_{l r r}=\operatorname{corr}\left(\epsilon_{x}, \epsilon_{x}^{*}\right)$. 

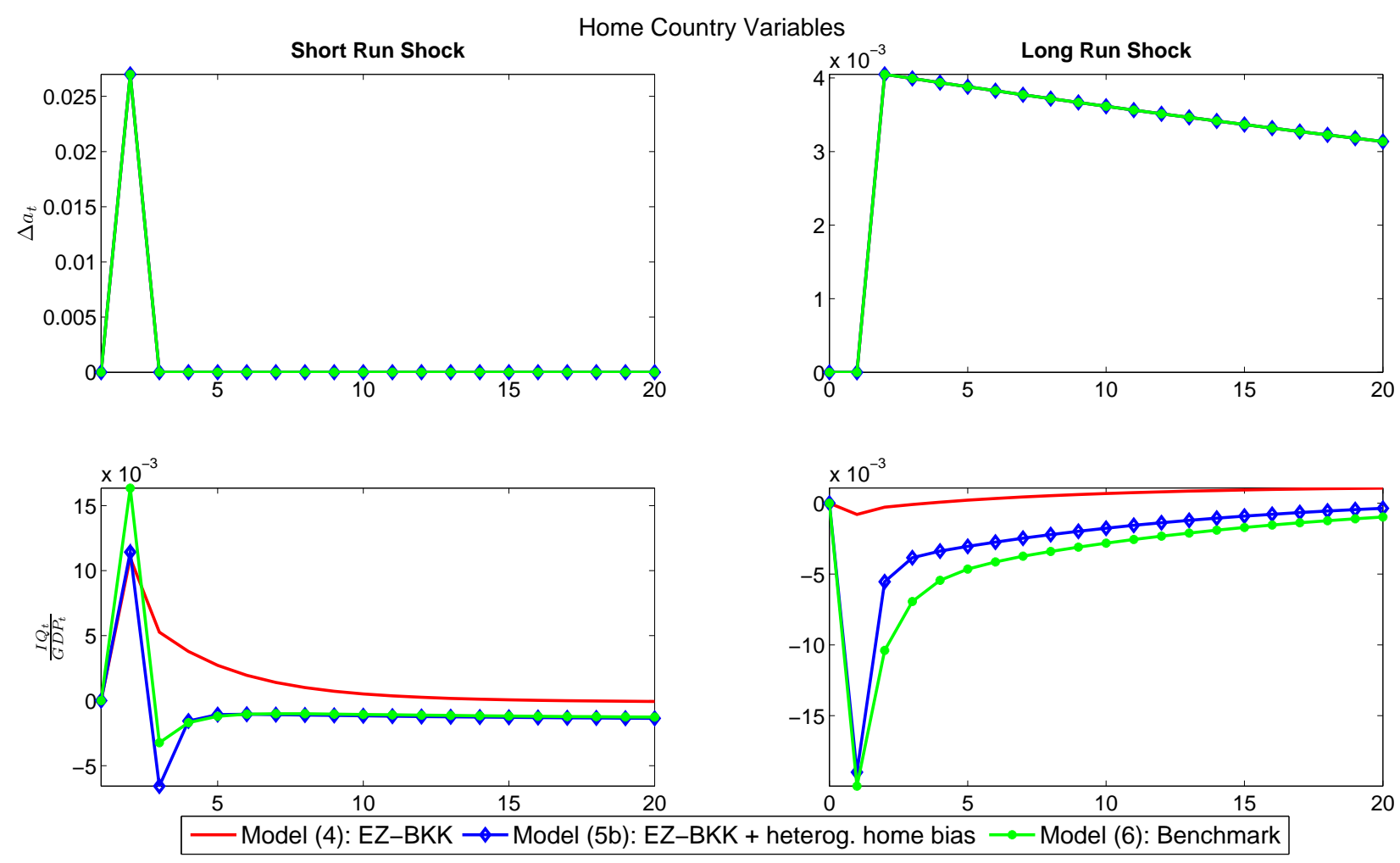

FIG. 5 - Investment share and capital vintages. This figure shows annual log deviations from the steady state. All the parameters are calibrated to the values reported in Table 2. Shocks to the home country productivity, $\epsilon_{a}$ and $\epsilon_{x}$, materialize at time 2. The short-run shock affects only the home country and has a magnitude $\sigma$. The long-run shocks affect both the home country with magnitude $\sigma_{x}$ and the foreign country with magnitude $\rho_{l r r} \sigma_{x}$, where $\rho_{l r r}=\operatorname{corr}\left(\epsilon_{x}, \epsilon_{x}^{*}\right)$. The variable $I Q_{t}$ is defined as $I_{x, t}+\bar{P} I_{x, t}^{*}$, where $\bar{P}$ is the terms of trade at the steady state.

investment declines more than under model (5b), consistent with the Ai et al. (2012) analysis.

This difference in the behavior of investment is not visible in Figure 3, in which we focus on the value of investment in local units. Upon the realization of long-run shocks, the value of investment is almost the same across models (6) and (5b), simply because the terms of trade worsen and make foreign investment more expensive. The fact that young vintages of capital do not immediately pick up the long-run productivity shock makes them less valuable, implying a delay in investment and a slow down in capital accumulation. 
By solving forward equation (5), we see that the value of capital, $Q_{t}$, is the expected present value of capital marginal productivity. When capital accumulation declines, the marginal productivity of capital increases because of decreasing marginal returns. The expected increase of capital productivity over the long-horizon leads to a substantial increase in $Q$. Consequently, as shown in Figure 4, the excess return of capital increases sharply exactly when the agent's marginal utility is low creating a sizeable equity premium.

We conclude this section by pointing out that heterogenous exposure to productivity shocks across vintage capitals makes the exchange rate depreciate more upon the realization of good domestic long-run news. The reason why this happens is that capital accumulation slows down in the domestic country more than in the foreign one. As a result, short-run consumption increases relatively more in the home economy than it does abroad, thus resulting in a larger fall of the pricing kernel in the home country. By no arbitrage, the domestic currency becomes weaker.

\subsection{Consumption Response to Long-run News}

Under the recursive risk-sharing mechanism studied by Colacito and Croce (2012), positive long-run news gives an incentive to the home country to export resources to the rest of the world in exchange for a reduction in wealth volatility. In Colacito and Croce's exchange economy, an increase in exports is feasible only if consumption growth slows down.

In our economy, however, the negative connection between consumption growth and net exports becomes weaker. As shown in Figure 3, upon the realization of positive long-run news the home country finds it convenient to export more by reducing investment. In our economy, home consumption increases upon the arrival of good news for the long-run, consistent with the empirical evidence proposed in the macroeconomic news literature (see, among others, Barsky and Sims 2011).

Using US and UK data, Colacito and Croce (2012) document that relative good longrun news to the home country produces a drop in domestic consumption. We argue that our model is consistent with this empirical observation as well, being the increase in consumption in Figure 3 observable only for small realizations of country- 
specific long-run news.

Specifically, in order to take into account the high international correlation of longrun news, we examine the case in which both countries receive good news of slightly different magnitudes. In Figure 6, we plot the response of quantities to a one-standard deviation long-run shock to home productivity assuming that the foreign country receives no news. We observe a decline in consumption, which is suggestive of a nonmonotone response of consumption growth to long-run news.

\subsection{Anomalies}

We conclude this section by showing the performance of our model with respect to three very well known anomalies in international finance. In Table 5, the first row refers to the Backus and Smith (1993) puzzle; that is, the lack of correlation between exchange rate growth and consumption growth cross-country differentials. We point out that all our models resolve the puzzle. The reason is that with GHH preferences there is a substantial difference between the behavior of the pricing kernels and the consumption aggregate growth rates.

In the second row of Table 5, we report the OLS coefficient of the uncovered interest parity regression, a typical measure of the so-called forward premium anomaly; that is the tendency of high interest rate currency to appreciate. In the data this coefficient is negative and is explained by counter-cyclical currency risk (see, among others, Lustig et al. (2011b)).

Even though our productivity shocks are homoscedastic, our model features endogenous counter-cyclical time-varying volatility in consumption and pricing kernels. This is a general feature of recursive risk-sharing schemes that generates time-varying currency risk premia (Colacito and Croce 2012). Only our benchmark calibration features enough time-varying volatility to generate a $\beta_{U I P}$ significantly lower than one.

Finally, the third row of Table 5 reports the difference between the cross-country correlation of consumption and output. BKK was the first paper to point out that with standard preferences consumption is more correlated than output, while in the data the opposite is true. BKK denote this fact as the quantity anomaly. When agents have recursive preferences, they have an incentive to share utility risk as opposed 
Home Country Variables
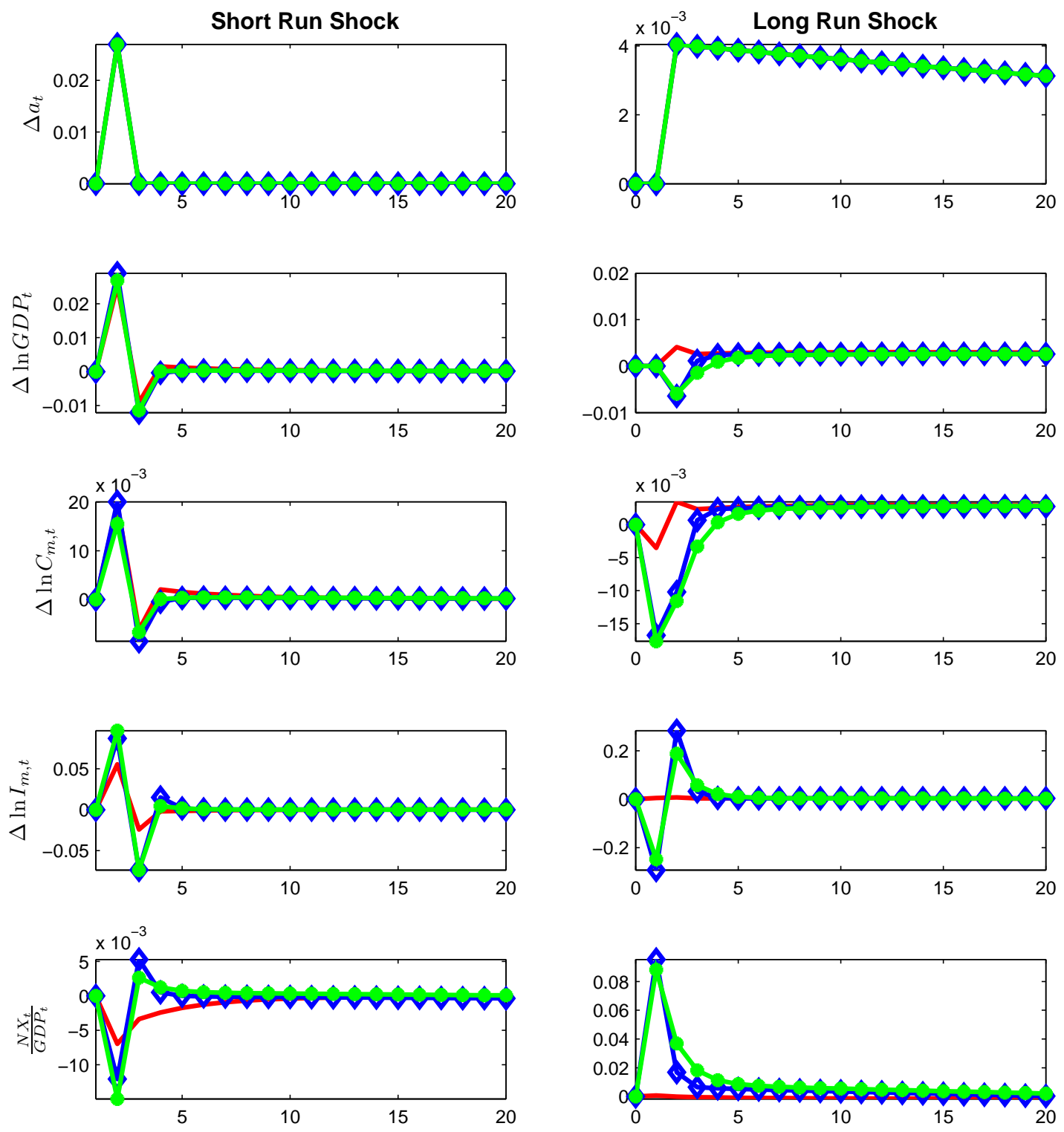

Model (4): EZ-BKK Model (5b): EZ-BKK + heterog. home bias M Model (6): Benchmark

FIG. 6 - Consumption response to extreme long-run news. This figure shows annual log deviations from the steady state. All the parameters are calibrated to the values reported in Table 2 . Shocks to the home country productivity, $\epsilon_{a}$ and $\epsilon_{x}$, materialize at time 2 . Both short-run and long-run shock affect only the home country with magnitude $\sigma$ and $\sigma_{x}$, respectively. 
TABLE 5: Anomalies

\begin{tabular}{|c|c|c|c|c|c|c|c|c|}
\hline odel & (1) & $\overline{(2)}$ & $\overline{(3)}$ & (4) & $\overline{(5)}$ & 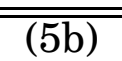 & 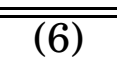 & $\overline{\text { Data }}$ \\
\hline $\operatorname{rr}\left(\Delta e, \Delta c_{r}\right.$ & -0.31 & -0.20 & -0.29 & -0.19 & -0.41 & 0.24 & -0.07 & -0.02 \\
\hline & 1.01 & 1.03 & 0.90 & 1.04 & 1.06 & 0.81 & 0.51 & -0.72 \\
\hline $\begin{array}{l}\operatorname{rrr}\left(\Delta c_{m}, \Delta c_{m}^{*}\right) \text { - } \\
\operatorname{rr}\left(\Delta y_{m}, \Delta y_{m}^{*}\right)\end{array}$ & 0.20 & 0.15 & 0.17 & 0.10 & 0.14 & -0.12 & -0.06 & -0.17 \\
\hline
\end{tabular}

Notes - Empirical moments are computed taking the US as home country. The entries for the models are obtained by a long-sample simulation.

to short-run consumption risk. That is, agents can equate their marginal utilities by keeping their continuation utilities highly correlated. In our production economy, equating utility dynamics is equivalent to equate long-run production dynamics. Ultimately, this is accomplished by having highly correlated capital accumulation across countries.

When investment home-bias is strong, equating long-run capital dynamics is relatively difficult. Hence the optimal allocation can be achieved only by keeping the correlation of short-run consumption bundles high enough. This explains why models (1)-(5) fail in reproducing the quantity anomaly, while both model (5b) and our benchmark model succeed. To better highlight this point, in Figure 7 we contrast the response of local investment and international investment flows across the BKK economy and our Benchmark model. This figure confirms that both investment growth and net exports of investment respond differently upon the realization of short- and long-run shocks under our Benchmark model. In the next section, we test these responses in the data and obtain positive results in favor of our recursive risk-sharing channel.

\section{Empirical Findings}

In this section, we provide direct empirical evidence supporting the implications of our model for the response of investment and net exports to both short- and long-run news. For a cross-section of G-7 countries starting in 1971, we find that investment and net exports of investment co-move with productivity shocks as prescribed by our complete markets mechanism. In section 6.1 , we describe in detail our empirical 
approach. We report our results in Table 6. A detailed description of our data sources is reported in the Appendix.

\subsection{Identification of Short- and Long-run Shocks}

We follow Colacito and Croce (2011) and Bansal et al. (2010) in identifying shortand long-run innovations to productivity by regressing Solow residuals on a set of predictive variables. These estimations are performed for Canada, France, Germany, Italy, Japan, the United Kingdom, and the United States. We adopt the convention of denoting the US as the home country. To study the robustness of our empirical results, we employ the following five sets of variables commonly used in the long-run risk literature to identify long-run components:

$$
\begin{aligned}
F_{1, t}^{i} & =\left[p d_{t}^{i}\right] \\
F_{2, t}^{i} & =\left[p d_{t}^{i}, r f_{t}^{i}\right] \\
F_{3, t}^{i} & =\left[p d_{t}^{i}, r f_{t}^{i}, \Delta c_{t}^{i}\right] \\
F_{4, t}^{i} & =\left[p d_{t}^{i}, r f_{t}^{i}, \Delta I_{t}^{i}\right] \\
F_{5, t}^{i} & =\left[p d_{t}^{i}, r f_{t}^{i}, \Delta c_{t}^{i}, \Delta I_{t}^{i}\right],
\end{aligned}
$$

where $p d, r f, \Delta c$, and $\Delta I$ denote the price-dividend ratio, the risk-free rate, the consumption growth, and the investments' growth rate, respectively. The index $i$ denotes each of the afore mentioned G-7 countries, and a Rest of the World (henceforth ROW) aggregate that features G-7 countries with the exclusion of the US. We denote this group of countries as G-6.

We employ three different ways of constructing the ROW aggregate productivity: i) a GDP weighted average of the G- 6 countries' productivity, ii) an investment weighted average of the G6 countries' productivity, and iii) a world Solow residual calculated directly from aggregated GDP, investment, and labor data of the G-6 countries. Specifically, world productivity in the last construction is calculated as $\frac{G D P}{K^{.66} L}$, where GDP is G-6 aggregated GDP, $\mathrm{K}$ is the capital stock computed from G-6 aggregated investment, and L measures the population-weighted average of hours worked per worker in the G-6 countries. We identify short- and long-run shocks by estimating the system of equations (4) in conjunction with the projection restrictions $z_{i, t, j}=\beta_{i, j} F_{j, t}^{i}$, for 

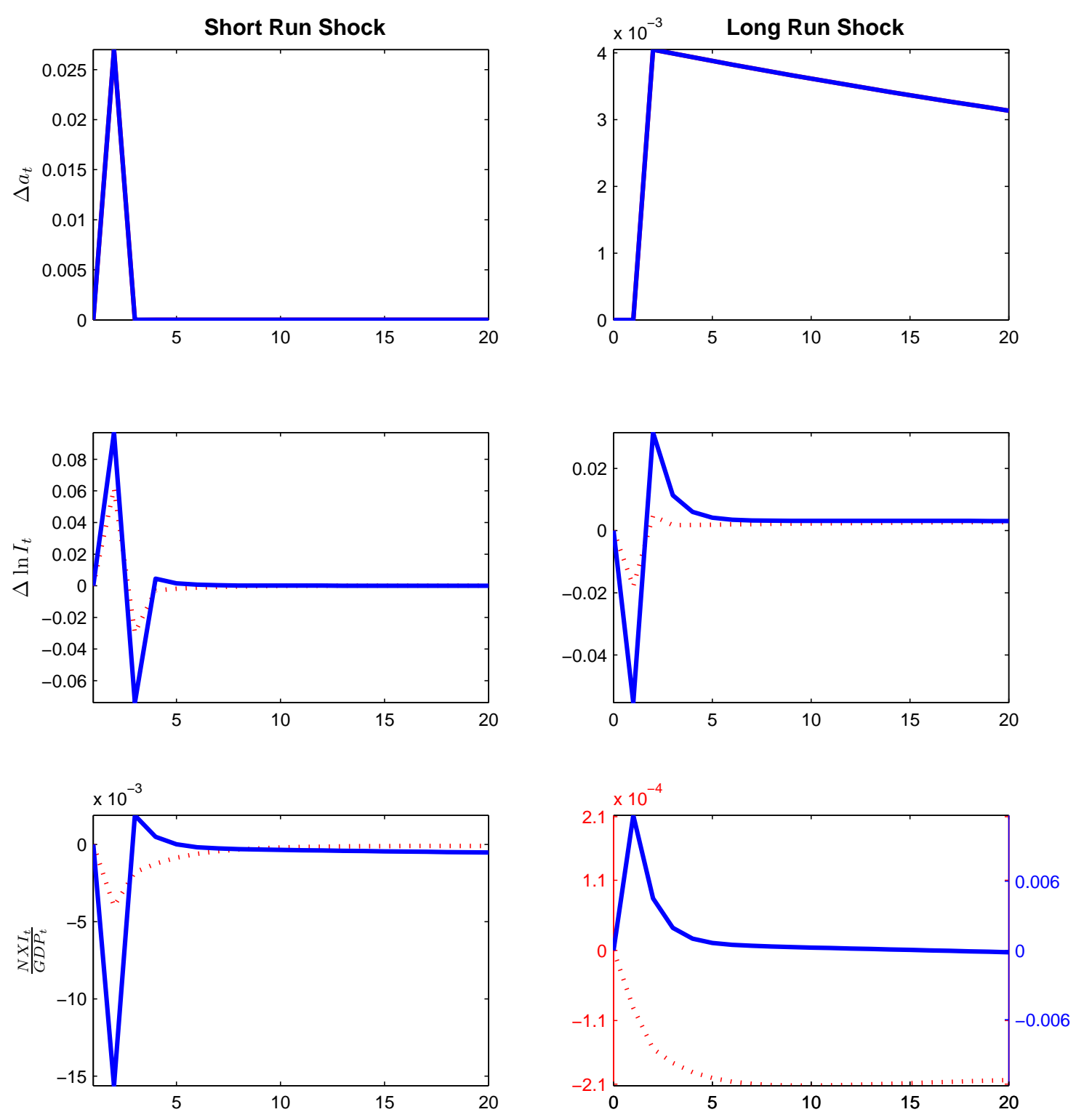

1 1 1 1 , ' Model (2): BKK with LRR Model (6): Benchmark

Fig. 7 - Investment Flows in the Short- and Long-Run. This figure shows annual log deviations from the steady state. All the parameters are calibrated to the values reported in Table 2 . Shocks to the home country productivity, $\epsilon_{a}$ and $\epsilon_{x}$, materialize at time 2 . The short-run shock only affects the home country with magnitude $\sigma$ and the long-run shock affects the home and foreign countries with magnitudes $\sigma_{x}$ and $\rho_{l r r} \sigma_{x}$, where $\rho_{l r r}=\operatorname{corr}\left(\epsilon_{x}, \epsilon_{x}^{*}\right)$. 
all countries $i$ reported above.

\subsection{Testable Implications}

Response of Investment. The model predicts that the difference between home and foreign investment should respond negatively (positively) to home (foreign) long-run news and positively (negatively) to home (foreign) short-run news (figure 7). We test this prediction by regressing investment growth differentials on short-run $\left(\varepsilon_{a}\right)$ shock differentials, long-run $\left(\varepsilon_{x}\right)$ shock differentials, and lagged long run risk differentials. We summarize our results in panel A of Table 6.

The sets of estimated coefficients labeled "GDP", "Investments", and "Solow" refer to the response of US investments relative to the ROW aggregate computed with the three methodologies discussed above. The rows labeled "system" refer to a panel estimation in which the dependent variables in the cross-section are the differentials between the US investment and each of the other G-7 countries, and in which all the loadings on the short- and long-run news are restricted to be the same for each country pair. We perform this last estimation exercise in order to gain statistical power from the cross-section of countries.

Several things ought to be noticed. First, the signs and the magnitudes of the estimated coefficients are always in line with the prediction of the model. This confirms the prediction of the model, according to which investments respond with opposite signs to short- and long-run innovations. Second, the results are robust to the alternative ways in which we aggregated ROW productivities. Third, as we enrich our set of predictive variables to include both prices and quantities, the statistical significance improves.

Interestingly, the estimates for the response of investment to long-run news are always strongly significant, highlighting the importance of long-lasting news on the dynamics of investment in major industrialized economies. Last but not least, when we focus on the "system" estimation, all coefficients are strongly significant. We interpret this result as confirming that (i) the data line up extremely well with our model, and (ii) in the few cases in which our coefficients are not significant the reason may be lack of statistical power due to cross-sectional aggregation. 
Net Export of Investment. As shown in Figure 7, our model suggests a novel mechanism according to which investment should flow away from countries that receive good long-run news, whereas BKK's model predicts the opposite result. We employ the same methodology described above to investigate the plausibility of this theoretical channel. Panel B of Table 6 documents that the data confirm our prediction that countries receiving good long-run productivity news experience an outflow of investment. Notice that these results is always statistically significant even when the estimated coefficients for the response of investment to short-run news are not. Again, the results benefit from the inclusion of both quantities and prices in the set of predictive variables. Furthermore, the system estimation confirms the ability of the panel estimation to compensate for the relatively short time-series.

\section{Concluding Remarks}

In this article, we investigate the role of long-term productivity risk on international risk-sharing and capital flows. Specifically, we start with a frictionless two-country and two-good production economy with time additive preferences as in Backus, Kehoe, and Kydland (1994) and modify it in the following three dimensions. First, we add Epstein and Zin (1989) recursive preferences and long-run growth shocks in the spirit of the recent long-run risk literature on exchange rates (Colacito and Croce 2011). Second, we use a higher home-bias in consumption than in investment as in Erceg et al. (2008). Third, we add heterogenous exposure of capital vintage to aggregate productivity as in $\mathrm{Ai}$, Croce, and $\mathrm{Li}$ (2012).

These modifications enable our model to produce the right amount of exchange rate volatility and resolves the Backus et al. (1992) quantity anomaly. Furthermore, these three elements allow us to obtain our most important prediction on international capital flows: under the optimal risk-sharing scheme, good long-run productivity news produces an immediate outflow of investment.

The introduction of heterogenous productivity across capital vintages as in $\mathrm{Ai}$ et al. (2012) enables us to obtain high and volatile capital excess returns with an equity premium close to $4 \%$. By doing so, we provide a new quantitative benchmark in international macro-finance. 
Future research should focus on the long-term fiscal and monetary policy implications of our model. It will be important to introduce also considerations about private and sovereign credit shocks and explore the role of markets incompleteness. It is also important to explore the role of capital flows for the determination of long-term price and shock elasticities (Borovička et al. 2011 and Borovička and Hansen 2011). 
TABLE 6: Empirical Analysis

\begin{tabular}{|c|c|c|c|c|c|c|c|}
\hline \multicolumn{8}{|c|}{ Panel A: Response of Investments } \\
\hline & & Benchmark & $\mathrm{pd}$ & pd,rf & pr,rf,dc & pr,rf,di & pd,rf,dc,di \\
\hline \multirow[t]{2}{*}{$\overline{G D P}$} & $\varepsilon_{a}$ & 2.53 & $\begin{array}{l}2.17^{* * *} \\
{[0.58]}\end{array}$ & $\begin{array}{c}2.31^{* * *} \\
{[0.56]}\end{array}$ & $\begin{array}{l}2.39^{* * *} \\
{[0.50]}\end{array}$ & $\begin{array}{c}2.67^{* * *} \\
{[0.53]}\end{array}$ & $\begin{array}{l}2.84^{* * *} \\
{[0.53]}\end{array}$ \\
\hline & $\varepsilon_{x}$ & -0.85 & $\begin{array}{c}-0.74 \\
{[4.01]}\end{array}$ & $\begin{array}{c}-1.42 \\
{[3.83]}\end{array}$ & $\begin{array}{c}-1.69 \\
{[1.53]}\end{array}$ & $\begin{array}{c}-3.69^{* * *} \\
{[1.07]}\end{array}$ & $\begin{array}{c}-4.10^{* * *} \\
{[1.02]}\end{array}$ \\
\hline \multirow[t]{2}{*}{ Investments } & $\varepsilon_{a}$ & 2.53 & $\begin{array}{l}1.91^{* * *} \\
{[0.55]}\end{array}$ & $\begin{array}{l}2.09^{* * *} \\
{[0.53]}\end{array}$ & $\begin{array}{l}2.25^{* * * *} \\
{[0.49]}\end{array}$ & $\begin{array}{l}2.60^{* * *} \\
{[0.50]}\end{array}$ & $\begin{array}{l}2.70^{* * *} \\
{[0.50]}\end{array}$ \\
\hline & $\varepsilon_{x}$ & -0.85 & $\begin{array}{c}0.37 \\
{[3.60]}\end{array}$ & $\begin{array}{c}-0.98 \\
{[3.29]}\end{array}$ & $\begin{array}{c}-1.88 \\
{[1.59]}\end{array}$ & $\begin{array}{c}-3.49^{* * *} \\
{[1.04]}\end{array}$ & $-3.77^{* * *}$ \\
\hline \multirow[t]{2}{*}{ Solow } & $\varepsilon_{a}$ & 2.53 & $\begin{array}{l}2.12^{* * *} \\
{[0.71]}\end{array}$ & $\begin{array}{l}2.16^{* * *} \\
{[0.70]}\end{array}$ & $\begin{array}{l}2.04^{* * *} \\
{[0.58]}\end{array}$ & $\begin{array}{l}2.23^{* * *} \\
{[0.76]}\end{array}$ & $\begin{array}{l}2.55^{* * *} \\
{[0.71]}\end{array}$ \\
\hline & $\varepsilon_{x}$ & -0.85 & $\begin{array}{c}-2.69 \\
{[5.97]}\end{array}$ & $\begin{array}{c}-2.96 \\
{[6.10]}\end{array}$ & $\begin{array}{c}-2.49^{*} \\
{[1.69]}\end{array}$ & $\begin{array}{c}-5.15^{* * *} \\
{[1.17]}\end{array}$ & $\begin{array}{c}-5.54^{* * *} \\
{[1.06]}\end{array}$ \\
\hline \multirow[t]{2}{*}{ System } & $\varepsilon_{a}$ & 2.53 & $\begin{array}{l}1.27^{* * *} \\
{[0.04]}\end{array}$ & $\begin{array}{l}1.27^{* * *} \\
{[0.04]}\end{array}$ & $\begin{array}{l}1.39^{* * * *} \\
{[0.04]}\end{array}$ & $\begin{array}{l}1.44^{* * * *} \\
{[0.04]}\end{array}$ & $\begin{array}{l}1.53^{* * *} \\
{[0.04]}\end{array}$ \\
\hline & $\varepsilon_{x}$ & -0.85 & $\begin{array}{r}0.30 \\
{[0.25]}\end{array}$ & $\begin{array}{c}-1.07^{* * *} \\
{[0.27]}\end{array}$ & $\begin{array}{r}0.04 \\
{[0.23]} \\
\end{array}$ & $\begin{array}{c}-3.82^{* * *} \\
{[0.11]}\end{array}$ & $\begin{array}{l}-3.31^{* * *} \\
{[0.11]}\end{array}$ \\
\hline \multicolumn{8}{|c|}{ Panel B: Response of Net Exports of Investments } \\
\hline & & Benchmark & $\overline{p d}$ & $\mathrm{pd}, \mathrm{rf}$ & pr,rf,dc & pr,rf,di & pd,rf,dc,di \\
\hline \multirow[t]{2}{*}{$\overline{G D P}$} & $\varepsilon_{a}$ & -0.35 & $\begin{array}{c}-0.19 \\
{[0.23]}\end{array}$ & $\begin{array}{c}-0.18 \\
{[0.22]}\end{array}$ & $\begin{array}{c}-0.20 \\
{[0.23]}\end{array}$ & $\begin{array}{c}-0.13 \\
{[0.33]}\end{array}$ & $\begin{array}{c}-0.08 \\
{[0.35]}\end{array}$ \\
\hline & $\varepsilon_{x}$ & 0.35 & $\begin{array}{c}0.66 \\
{[0.90]}\end{array}$ & {$\left[\begin{array}{c}0.62 \\
{[0.71]}\end{array}\right.$} & $\begin{array}{l}1.14^{* * *} \\
{[0.42]}\end{array}$ & $\begin{array}{l}0.64^{* * *} \\
{[0.17]}\end{array}$ & $\begin{array}{c}0.47^{* *} \\
{[0.20]}\end{array}$ \\
\hline \multirow[t]{2}{*}{ Investments } & $\varepsilon_{a}$ & -0.35 & $\begin{array}{c}-0.16 \\
{[0.22]}\end{array}$ & $\begin{array}{c}-0.15 \\
{[0.22]}\end{array}$ & $\begin{array}{c}-0.18 \\
{[0.22]}\end{array}$ & $\begin{array}{c}-0.12 \\
{[0.32]}\end{array}$ & $\begin{array}{c}-0.06 \\
{[0.34]}\end{array}$ \\
\hline & $\varepsilon_{x}$ & 0.35 & $\begin{array}{c}0.54 \\
{[0.94]}\end{array}$ & $\begin{array}{c}0.57 \\
{[0.66]}\end{array}$ & $\begin{array}{l}1.07^{* * *} \\
{[0.35]}\end{array}$ & $\begin{array}{l}0.60^{* * *} \\
{[0.16]}\end{array}$ & $\begin{array}{l}0.44^{* * *} \\
{[0.18]}\end{array}$ \\
\hline \multirow[t]{2}{*}{ Solow } & $\varepsilon_{a}$ & -0.35 & $\begin{array}{c}-0.26 \\
{[0.25]}\end{array}$ & $\begin{array}{c}-0.23 \\
{[0.22]}\end{array}$ & $\begin{array}{c}-0.26 \\
{[0.22]}\end{array}$ & $\begin{array}{c}-0.17 \\
{[0.31]}\end{array}$ & $\begin{array}{l}-0.10 \\
{[0.34]}\end{array}$ \\
\hline & $\varepsilon_{x}$ & 0.35 & {$\left[\begin{array}{c}1.12 \\
{[1.02]}\end{array}\right.$} & $\begin{array}{c}0.74 \\
{[0.81]}\end{array}$ & $\begin{array}{l}1.26^{* * * *} \\
{[0.54]}\end{array}$ & $\begin{array}{l}0.73^{* * *} \\
{[0.19]}\end{array}$ & $\begin{array}{l}0.51^{* *} \\
{[0.22]}\end{array}$ \\
\hline \multirow[t]{2}{*}{ System } & $\varepsilon_{a}$ & -0.35 & $\begin{array}{c}-0.24^{* * *} \\
{[0.01]}\end{array}$ & $\begin{array}{c}-0.17^{* * *} \\
{[0.02]}\end{array}$ & $\begin{array}{c}-0.19^{* * *} \\
{[0.02]}\end{array}$ & $\begin{array}{c}-0.12^{* * *} \\
{[0.02]}\end{array}$ & $\begin{array}{c}-0.07^{* * *} \\
{[0.01]}\end{array}$ \\
\hline & $\varepsilon_{x}$ & 0.35 & $\begin{array}{l}1.26^{* * *} \\
{[0.11]}\end{array}$ & $\begin{array}{l}0.93^{* * *} \\
{[0.05]}\end{array}$ & $\begin{array}{l}0.90^{* * *} \\
{[0.04]}\end{array}$ & $\begin{array}{l}0.43^{* * *} \\
{[0.04]}\end{array}$ & $\begin{array}{l}0.22^{* * *} \\
{[0.03]}\end{array}$ \\
\hline
\end{tabular}

Notes - The top panel reports the response of the difference of investment growth between the US and the rest of the world (G7 countries excluding the US) to the difference of short-run shocks $\left(\varepsilon_{a}\right)$, the difference of long-run shocks $\left(\varepsilon_{x}\right)$, and the difference of lagged predictive components (not reported in the table). The column labeled "Benchmark" reports the coefficients estimated by simulating the benchmark version of the model and regressing the difference of investment growth between the home and the foreign country on the difference of short-run shocks, long-run shocks, and lagged predictive components. The columns labeled "pd", "pd,rf", "pd,rf,dc", "pd,rf,di", and "pd,rf,dc,di" refer to the cases in which the long-run risks were estimated by regressing Solow residuals on the corresponding set of predictive variables. The row labeled "GDP" ("Investments") refers to the case in which ROW productivity was created by a GDP (Investment) weighted average of individual G6 country productivities. The row labeled "Solow" refers to the case in which ROW productivity was created by calculating Solow residuals from aggregated GDP, investment, and labor data of the G6 countries. The row labeled "System" show the results for the case of the panel estimation in which the dependent variables in the cross-section are the difference between US investment growth and each of the other G-7 countries' investment growth, and in which all the loadings on the short- and long-run news are restricted to be the same for each country pair. The numbers in brackets are heteroscedasticity adjusted standard errors. One, two, and three stars denote $10 \%, 5 \%$, and $1 \%$ significance of a one tailed test that the sign of the corresponding estimated coefficient is different from the sign predicted by the model. Panel B repeats the same analysis for the case in which the dependent variable is the Net Exports of Investments. 


\section{References}

Ai, H., M. M. Croce, and K. Li. 2012. Toward a Quantitative Genaral Equilibirum Asset Pricing Model with Intangible Capital. Review of Financial Studies. Forthcoming.

Alessandria, G., J. P. Kaboski, and V. Midrigan. 2011. Us trade and inventory dynamics. American Economic Review 101.

Backus, D., and G. Smith. 1993. Consumption and real exchange rates in dynamic exchange economies with nontraded goods. Journal of International Economics 35:297-316.

Backus, D., S. Foresi, and C. Telmer. Affine term structur models and the forward premium anomaly. Technical report 2001.

Backus, D. K., P. J. Kehoe, and F. E. Kydland. 1992. International real business cycles. Journal of Political Economy 100(4):745-775.

Backus, D. K., P. J. Kehoe, and F. E. Kydland. 1994. Dynamics of the trade balance and the terms of trade: The j-curve? The American Economic Review 84(1):pp. 84-103.

Bai, Y., and J. Zhang. 2010. Solving the Feldstein-Horioka Puzzle with Financial Frictions. Econometrica.

Bansal, R., and I. Shaliastovich. 2010. A long-run risks explanation of predictability puzzles in bond and currency markets. Working Paper.

Bansal, R., and A. Yaron. 2004. Risks for the long run: A potential resolution of asset pricing puzzles. Journal of Finance 59:1481-1509.

Bansal, R., D. Kiku, and A. Yaron. 2010. Risks for the long run: Estimation and inference. Working Paper.

Barsky, B., and E. Sims. 2011. News Shocks and Business Cycles. Journal of Monetary Economics 58(3):273-289.

Baxter, M., and M. J. Crucini. 1995. Business cycles and the asset structure of foreign trade. International Economic Review 36.

Borovička, J., and L. Hansen. 2011. Examining macroeconomic models through the lens of asset pricing. Working Paper, Chicago University. 
Borovička, J., L. Hansen, M. Hendricks, and J. Scheinkman. 2011. Risk-price dynamics. Journal of Financial Econometrics 9:3-65.

Brandt, W., J. Cochrane, and P. Santa-Clara. 2006. International risk sharing is better than you think, or exchange rates are too smooth. Journal of Monetary Economics 53(4):671-698.

Campbell, J. 2003. Consumption-based asset pricing. forthcoming in Handbook of the Economics of Finance. George Constantinides, Milton Harris, and Rene Stulz eds., NorthHolland, Amsterdam.

Colacito, R. 2008. Six anomalies looking for a model. a consumption based explanation of international finance puzzles. Working Paper, Department of Finance, University of North Carolina, Chapel Hill NC.

Colacito, R., and M. M. Croce. 2011. Risks for the Long Run and the Real Exchange Rate. Journal of Political Economy 119(1):153-182.

Colacito, R., and M. M. Croce. 2012. International Asset Pricing with Recursive Preferences. Journal of Finance. Forthcoming.

Croce, M. M. 2008. Long-Run Productivity Risk: A New Hope For Production-Based Asset Pricing? Working paper, Kenan-Flagler Business School, UNC.

Epstein, L. G., and S. E. Zin. July 1989. Substitution, Risk Aversion, and the Temporal Behavior of Consumption and Asset Returns: A Theoretical Framework. Econometrica 57(4): 937-69.

Erceg, C., L. Guerrieri, and C. Gust. 2008. Trade Adjustment and the Composition of Trade. Journal of Economic Dynamics and Control 32(8).

Garca-Feijo, L., and R. D. Jorgensen. 2010. Can Operating Leverage Be the Cause of the Value Premium? Financial Management.

Greenwood, J., Z. Hercowitz, and G. Huffman. 1988. Investment capacity utilization and the real business cycle. American Economic Review 78.

Heathcote, J., and F. Perri. 2004. Financial globalization and real regionalization. Journal of Economic Theory 119.

Kehoe, P. J., and F. Perri. 2002. International business cycles with endogenous incomplete markets. Econometrica 70:907-928. 
Kose, M. A., C. Otrok, and C. H. Whiteman. 2003. International Business Cycles: World, Region, and Country-Specific Factors. The American Economic Review 93.

Kose, M. A., C. Otrok, and C. H. Whiteman. 2008. Understanding the evolution of world business cycles. Journal of International Economics 75.

Lewis, K. 2011. Global Asset Pricing. Annual Reviews of Financial Economics.

Lustig, H., and A. Verdelhan. 2007. The cross section of foreign currency risk premia and consumption growth risk. American Economic Review 97:89-117.

Lustig, H., N. Roussanov, and A. Verdelhan. 2011a. Common risk factors in currency markets. Forthcoming in the Review of Financial Studies.

Lustig, H., N. Roussanov, and A. Verdelhan. 2011b. Counter-cyclical currency risk premia. Working paper, Wharton.

Petrosky-Nadeau, N. 2011. Endogenous flows of foreign direct investment and international real business cycles. Working paper, CMU.

Raffo, A. 2008. Net exports,consumption volatility and international business cycle models. Journal of International Economics.

Stockman, A. C., and L. L. Tesar. 1995. Tastes and Technology in a Two-Country Model of the Business Cycle: Explaining International Comovements. The American Economic Review 85.

Tretvoll, H. 2012. Real exchange rate variability in a two-country cycle model. Working paper, NYU. 


\section{A: Data Sources}

Consumption, investment, exports, and import data are from the OECD and are PPP adjusted in 2005 US dollars. Labor data is from Raffo (2008). Net exports of investment data is from BEA's NIPA tables 1.1.5 and 4.2.5. All quantities are deflated using the GDP deflator from NIPA table 1.1.9. The risk-free rate is calculated as the nominal risk-free rate minus the inflation rate, where both rates are obtained from the IMF (for the United Kingdom, the retail index is used to calculate inflation). Germany and Italy's risk-free rate series calculated from the IMF begins in 1975 and 1976, respectively. To extend the data back to 1971, riskfree interest rates are obtained from Campbell (2003). Price-dividend ratio for the United States comes from Colacito and Croce (2011) and price-dividend ratios for the rest of the G7 is calculated using Ken French's cum and ex-dividend country value-weighted dollar index returns (using 'All 4 Data Items Not Reqd' series). French's data begin in 1977; to extend data to 1971, price-divdend ratios from Campbell (2003) are included for 1971-1976. 